\title{
Application of Fundamental Techniques for Physicochemical Characterizations to Understand Post-Formulation Performance of Pharmaceutical Nanocrystalline Materials
}

\author{
Bwalya A. Witika ${ }^{1,2, *}$, Marique Aucamp ${ }^{3}$, Larry L. Mweetwa ${ }^{2}$ and Pedzisai A. Makoni ${ }^{4, *(D)}$ \\ 1 ApotheCom I A MEDiSTRAVA Company (Medical Division of Huntsworth), London WC2A 1AN, UK \\ 2 Department of Pharmacy, DDT College of Medicine, Gaborone P.O. Box 70587, Botswana; \\ larrymweetwa1@gmail.com \\ 3 School of Pharmacy, Faculty of Natural Sciences, University of the Western Cape, Private Bag X17, \\ Bellville 7535, South Africa; maucamp@uwc.ac.za \\ 4 Division of Pharmacology, Faculty of Pharmacy, Rhodes University, Makhanda 6140, South Africa \\ * Correspondence: bwalya.witika@apothecom.com (B.A.W.); p.makoni@ru.ac.za (P.A.M.)
}

check for

updates

Citation: Witika, B.A.; Aucamp, M.; Mweetwa, L.L.; Makoni, P.A.

Application of Fundamental

Techniques for Physicochemical

Characterizations to Understand

Post-Formulation Performance of

Pharmaceutical Nanocrystalline

Materials. Crystals 2021, 11, 310.

https://doi.org/10.3390/

cryst 11030310

Academic Editor: Etsuo Yonemoch

Received: 28 February 2021

Accepted: 17 March 2021

Published: 21 March 2021

Publisher's Note: MDPI stays neutral with regard to jurisdictional claims in published maps and institutional affiliations.

Copyright: (c) 2021 by the authors. Licensee MDPI, Basel, Switzerland. This article is an open access article distributed under the terms and conditions of the Creative Commons Attribution (CC BY) license (https:/ / creativecommons.org/licenses/by/ $4.0 /)$.

\begin{abstract}
Nanocrystalline materials (NCM, i.e., crystalline nanoparticles) have become an important class of materials with great potential for applications ranging from drug delivery and electronics to optics. Drug nanocrystals (NC) and nano co-crystals (NCC) are examples of NCM with fascinating physicochemical properties and have attracted significant attention in drug delivery. NCM are categorized by advantageous properties, such as high drug-loading efficiency, good long-term physical stability, steady and predictable drug release, and long systemic circulation time. These properties make them excellent formulations for the efficient delivery of a variety of active pharmaceutical ingredients (API). In this review, we summarize the recent advances in drug NCM-based therapy options. Currently, there are three main methods to synthesize drug NCM, including top-down, bottom-up, and combination methods. The fundamental characterization methods of drug NCM are elaborated. Furthermore, the applications of these characterizations and their implications on the post-formulation performance of NCM are introduced.
\end{abstract}

Keywords: nanocrystalline materials; physicochemical characterization; vibrational spectroscopy; X-ray analysis; thermal analysis; critical quality attributes

\section{Introduction}

There has been an increasing interest in developing drug delivery systems that circumvent the challenges associated with conventional drug delivery [1]. Among those challenges are poor drug solubility and formulation stability, low bioavailability, and undesirable side effect profiles [1]. Solutions to some of these shortcomings have been suggested and have included the use of nanotechnology. Nanotechnology is defined as the engineering and manufacture of materials at an atomic or molecular scale resulting in nanoparticles [2]. The definition of nanoparticles regarding particle size is constantly under deliberation. This has resulted in different disciplines adopting different definitions. As an example, colloid chemistry describes nanoparticles as having particle sizes below $100 \mathrm{~nm}$ or and in some instances $20 \mathrm{~nm}$. In the pharmaceutical domain, nanoparticles are identified as having a size $\leq 1000 \mathrm{~nm}$ [3]. Therefore, in this review, we define nanocrystalline (NCM) as crystalline materials composed of nanoparticles having dimensions $<1000 \mathrm{~nm}[4,5]$. Some of the desirable properties of nanoparticles are that they often maintain crystallinity after their manufacturing process. Crystallinity relates to the extent of structural order in a solid and is characterized by atomic or molecular arrangement being regular and periodic - the production of nanoparticles that exhibit crystallinity results in the formation of NCM. The production of NCM requires a combination of crystal engineering and nanotechnological approaches. 
Crystal engineering is the manipulation of non-covalent interactions between molecular or ionic components for the rational design of solid-state structures that may exhibit desirable electrical, magnetic, and optical properties [6]. Intermolecular hydrogen bonds can be used to assemble supramolecular structures that, at the very minimum, control or influence dimensionality [6,7]. Crystal engineering can also be described as the knowledge of intermolecular interactions in the context of crystal packing and the use of such understanding in the design of new solid materials with desirable physicochemical properties $[8,9]$.

Co-crystals are single-phase crystalline solids that are composed of two or more different molecular or ionic compounds, generally in a stoichiometric ratio [10]. Co-crystals can be constructed using several types of molecular interactions such as hydrogen bonds, ionic interactions, $\pi-\pi$ stacking, and van der Waal's forces [11-14].

Two general methods are used to manufacture NCM. The first utilizes collision forces to cause particle size reduction to nanometer dimensions and is called the top-down approach $[15,16]$, while the second approach makes use of nucleation and crystal growth. A suitable stabilizer is utilized to prevent crystal growth into the micrometre range and is termed the bottom-up approach $[17,18]$. In the broadest sense, NCM used in drug delivery can be subdivided into organic and inorganic NCM. In this review, we focus on the characterization of organic NCM for the delivery of active pharmaceutical ingredients (API). More specifically, we highlight the characterization techniques most applicable to NC and NCC as models NCM for the delivery of API.

Drug NC are crystals with a size in the nanometre range. This means that they are nanoparticles that exhibit a high degree of crystallinity [3]. Similarly, drug NCC are crystalline solids existing as a single phase that is composed of different molecules that have nanometric dimensions [19]. In the case of both types of the aforementioned NCM, crystal growth from the nanometer to the micrometre range is inhibited by stabilizers [20-22].

In drug delivery, these NCM have found a broad range of applications in circumventing the shortcomings of conventional drug delivery while exhibiting flexibility regarding the routes of administration.

When applied in transdermal delivery, NCM are expected to pack tightly and form a dense layer that hydrates the skin and improves drug penetration and permeation. Dissolved NCM may be topically retained for a sufficient period and offer sustained API release [23]. As a way of example, a formulation of L-ascorbic acid demonstrated longterm stability as NC dispersed in an oil base. The NC oil dispersion exhibited improved penetration and stability when compared to conventional technologies [24].

Oral administration remains the most preferred route and is generally considered a safe and suitable drug delivery route [25]. Dissolution is often the rate-determining step for absorption, and because NCM generally provide a larger surface area for dissolution, increase saturation solubility, and ultimately increase the dissolution extent, they have been shown to enhance API absorption [26]. Rapamune ${ }^{\circledR}$, a formulation composed of sirolimus NC blended with additional excipients and directly compressed into tablets, was the first US FDA-approved nanocrystalline drug launched in 2000 by Wyeth Pharmaceuticals (Madison, NJ, USA) for oral use. The oral bioavailability of the API from the nanocrystalline tablets was $21 \%$ higher than that of sirolimus delivered in aqueous solution [27]. Similarly, the advantages of nano-drug delivery have been applied to modulate the pharmacokinetic profile of aprepitant $\left(\right.$ Emend $\left.^{\circledR}\right)$, which requires delivery at an absorption window in the gastrointestinal tract [28].

Drug delivery to the eye is hindered by pharmacokinetic, physiological, and in some instance's environmental factors. Conventional formulations are rapidly cleared from the site of administration due to rapid eye movement such as blinking and/or lacrimation, resulting in low ocular bioavailability. Consequently, repeated dosing and subsequent reduction in adherence results in poor clinical outcomes. Frequent dosing may also lead to an increase in dose-dependent side effects [29,30]. NCM technologies can play a critical role in drug delivery to the eye by improving the solubility of poorly soluble API. This was 
explored and showed favourable outcomes when utilized in formulations containing budesonide, dexamethasone, hydrocortisone, prednisolone [31], and fluorometholone [31,32]. A technique based on combining microfluidic and milling technologies resulted in the production of NC of hydrocortisone. The ocular bioavailability of the NC was evaluated in vivo using albino rabbits. Extended duration of action and a significant improvement in the area under the curve (AUC) for hydrocortisone delivered using the NC were observed when compared to coarse hydrocortisone [33].

Parenteral drug delivery ensures a shorter onset of action, higher bioavailability, and use of reduced doses when compared to oral drug delivery. These benefits are ideal target parameters for drug delivery; however, the use of the intravenous route is challenging as only a limited number of solvents and excipients can be used during formulation development. This is due to an increased possibility of adverse outcomes in addition to those caused by the API. NC of ascularine [34], melarsoprol [35], oridonin [36], itraconazole [37], and curcumin [38] have been successfully developed and resulted in increases in their $C_{\max }$ and $\mathrm{AUC}_{0-\infty}$.

Targeted delivery approaches have been implemented in combination with NC and NCC technology for drugs that exhibit low bioavailability, poor aqueous solubility and stability, and limited in vitro-in vivo correlations (IVIVC) [39,40]. Buparvaquone NC suspended in a mucoadhesive system of $\mathrm{Carbopol}^{\circledR} 934,971,974,980$ or $0.5 \% w / w$ Noveon ${ }^{\circledR}$ AA-1 was used for targeting the gastrointestinal parasite, Cryptosporidium parvum, and resulted in better targeting and greater stability than pure buparvaquone [41].

Surface modification of NCM can also be used to reduce the potential toxicity of API to selected cell lines. For instance, surface modification of lamivudine-zidovudine NCC with sodium dodecyl sulphate (SDS) and $\alpha$-tocopheryl polyethylene glycol succinate 1000 (TPGS 1000) was reported to have reduced cytotoxic effect on HeLa cells [42].

Despite their success in drug delivery, NCM have to undergo rigorous characterization prior to their use in humans. Many of these techniques are centred on developing quality into the product and ensuring that critical process parameters (CPP) do not have a significant impact on the critical quality attributes (CQA) of the product [43]. Consequently, the resultant NC or NCC meets the quality target product profile (QTPP) that could lead to inclusion into suitable dosage forms and subsequent human use.

Formulation and morphology of drug NCM, including fundamental characterizations and their implications on post-formulation performance are described below.

\section{Formulation and Morphology of NCM}

Two formulation approaches have been shown to produce NC viz., the top-down technique that relies on shear forces for particle size reduction into the nanometre range $[15,16]$ and the bottom-up approach that allows for nucleation and growth of individual monomers, which remain nanosized because of a stabiliser [17,18].

\subsection{Top-Down Production Approaches}

High-energy mechanical forces are involved in top-down approaches and are provided by media milling (MM) techniques, including NanoCrystals ${ }^{\circledR}$ or high-pressure homogenization (HPH), Insoluble Drug Delivery-Particles (IDD- $\mathrm{P}^{\mathrm{TM}}$ ), DissoCubes ${ }^{\circledR}$, and Nanopure ${ }^{\circledR}$, to comminute large crystals into crystals of smaller dimensions [16,44]. Topdown processes are commonly used for the preparation of crystalline nanoparticles [45] and are flexible following scale-up production [46]. Consequently, the process has been widely adopted for commercial scale preparation of nanocrystals. With the exception of Triglides produced by IDD- $\mathrm{P}^{\circledR}$, the majority of the other products are commercially produced using NanoCrystals ${ }^{\circledR}$. However, high-energy input, lengthy operational units, and the potential to introduce contamination from the use of grinding media are drawbacks of this technology. For instance, high pressures of up to 1700 bar with 50-100 cycles of homogenisation are often required to achieve a desired particle size distribution and size $[3,47]$. Furthermore, the milling time varies from hours to days depending on the 
properties of the API, milling media, and extent of required particle size reduction [46,48]. Since contamination from grinding media may lead to unexpected side-effects and/or toxicities, the top-down production method is not a suitable option for the preparation of parenterally administered NC $[49,50]$.

\subsubsection{HPH (IDD-P ${ }^{\circledR}$, DissoCubes ${ }^{\circledR}$, and Nanopure ${ }^{\circledR}$ )}

During the process of HPH, API-loaded suspensions are introduced into a highpressure homogeniser and forced through a narrow orifice in sudden bursts under high pressure. Owing to this, cavitation, high-shear forces, and particle collisions result in fracture of API particles. Generally, the HPH method occurs via the following steps: of (i) crude API powder is dispersed in pure solution or in a solution containing a stabiliser, (ii) a reduction of particle size occurs by high-speed shearing or homogenization under low pressure, (iii) HPH is used to achieve the target particle size and size distribution.

Based on the instrumentation and solutions used, HPH processes can be sub-divided into three patented technologies, including microfluidics for IDD- $\mathrm{P}^{\circledR}$ technology, piston gap homogenisation for DissoCubes ${ }^{\circledR}$ in aqueous media, and Nanopure ${ }^{\circledR}$ for non-aqueous media. Nonetheless, attainment of formulation optimization requires an investigation into the effect of various formulation and process parameters.

\subsubsection{MM (NanoCrystals ${ }^{\circledR}$ )}

In this technique, NC are obtained by subjecting API to a media-milling process. The media mill consists of a milling chamber, milling shaft, and recirculation chamber [16]. The generation of high energy and shear forces as a result of milling media and API collisions provide the requisite energy to disintegrate microparticulate drugs into nanosized particles. The milling media may be glass, zirconium oxide, or highly cross-linked polystyrene resin. During this process, the milling chamber is initially charged with milling media, water or buffer, API and stabiliser. The system is then rotated at a very high shear rate, and the milling process is performed under controlled temperature conditions in either batch or recirculation mode. When using the batch mode, dispersions with unimodal size distribution profiles and mean diameters $<200 \mathrm{~nm}$ are produced in approximately 30-60 min. The media milling process can successfully process micronized and unmicronized drug crystals. Following the optimization of formulation and the process parameters, minimal batch-to-batch variability is observed when evaluating the quality of resultant dispersion(s).

However, the generation and introduction of milling media residue into the final product due to media erosion is of major concern. This phenomenon could be problematic during the production of nanosuspensions intended for chronic administration. However, the advent of polystyrene resin-based milling media has led to the reduced occurrence of the aforementioned issue, for which residual polymeric monomers are typically $50 \mathrm{ppb}$ and the residuals generated during the milling process of not more than (NMT) $0.005 \%$ $w / w$ of the final product or resulting solid dosage form [50,51].

MM has been used with considerable success to yield NCC containing furosemide and caffeine, acetamide, urea and nicotinamide as co-formers, carbamazepine, and separately indomethacin with the co-former saccharin [52]. Initially, the manufacture of micronized co-crystals of each was performed using liquid assisted grinding (LAG) with methanol, acetonitrile, or acetone, or using a slurry technique [52]. Subsequently, the resultant cocrystals were dispersed in a solution containing $0.5 \% w / v$ HPMC and $0.02 \% w / v$ sodium dodecyl sulphate (SDS) in distilled water and wet-milled using zirconia beads. Wet-milling was conducted three times at $2000 \mathrm{rpm}$ for $2 \mathrm{~min}$ and then $500 \mathrm{rpm}$ for $2 \mathrm{~min}$ cycles. The milling chamber was maintained at $-10{ }^{\circ} \mathrm{C}$ during the process. Lastly, the resulting suspension and zirconia bead mixture was transferred to a centrifuge filter-mesh chamber to separate and collect the suspensions at $400 \mathrm{rpm}$ for $1 \mathrm{~min}$ [52].

Itraconazole nanosuspensions have also been manufactured using wet-milling with Tween ${ }^{\circledR} 80$ dissolved in a $20 \mathrm{~mL}$ vial containing $5 \mathrm{~mL}$ demineralised water, followed by 
the dispersion of $250 \mathrm{mg}$ itraconazole in this aqueous phase. Different concentrations of dicarboxylic acid co-formers (maleic, adipic, glutaric, and succinic acid) were dissolved in the suspension. Zirconium oxide milling pearls $(30 \mathrm{~g})$ of $0.5 \mathrm{~mm}$ diameter were added to the suspension. The vials were placed on a roller-mill and grinding performed at $150 \mathrm{rpm}$ for $60 \mathrm{~h}$ after which the nanoparticles were separated from the pearls by sieving [53].

Witika et al. demonstrated the use of (MM) to produce NCC of lamivudine and zidovudine. The initial step involved the use of solution co-crystallisation to produce co-crystals. During the second step, NCC were manufactured using a top-down method, specifically, wet media milling using an in-house modified jigsaw as the milling chamber. A $115 \mathrm{mg}$ aliquot of the harvested or dried co-crystal was placed in a $1.5 \mathrm{~mL}$ stainless steel milling chamber. The milling liquid comprised of different $\% w / v$ TPGS 1000 and SLS concentrations as defined by experimental design software. Stainless-steel balls were used as milling media with milling times of 10,20 , or $30 \mathrm{~min}$ at a constant milling speed of $65 \mathrm{~Hz}$ [54].

\subsubsection{Bottom-Up Production Approaches}

Bottom-up approaches promote the growth of NC from solution via two crucial steps viz., nucleation and crystal growth. Nucleation is crucial in the production of small uniform NC. An increase in nucleation rate results in an increase in the number of nuclei formed from the supersaturated solution, leading to a decrease in supersaturation and thus reduced growth for each nucleus [49]. If a large number of nuclei are produced concurrently during nucleation, a narrow particle size distribution is likely to occur [49]. Therefore, it is essential to promote rapid and homogeneous nucleation when using a bottom-up process. In general, the drug solution and an anti-solventare combined using conventional mixing equipment, e.g., a magnetic stirrer or an agitator blade [55]. Nucleation can be triggered by mixing with an anti-solvent or removal of solvent [18] or introduction of sonic waves to induce sonoprecipitation $[55,56]$. Sonoprecipitation has been used successfully to develop NCC to produce caffeine-containing co-crystals using a single-solvent approach by separately adding $60 \mathrm{mg}$ caffeine and $48 \mathrm{mg}$ of 2,4-dihydroxybenzoic acid (DHBA) in $7 \mathrm{~mL}$ and $242 \mathrm{~mL}$ acetone, respectively. The solutions were rapidly injected into $200 \mathrm{~mL}$ of hexane at approximately $0{ }^{\circ} \mathrm{C}$ and sonicated for $15 \mathrm{~s}$ in a cleaning bath. A two-solvent approach using the same procedure with $125 \mathrm{mg}$ of caffeine and $99 \mathrm{mg}$ DHBA dissolved separately in $1 \mathrm{~mL}$ chloroform and $600 \mathrm{~mL}$ acetone and rapidly injected into $100 \mathrm{~mL}$ of hexane at approximately $0{ }^{\circ} \mathrm{C}$ was also successful in the production of co-crystals, with Span ${ }^{\circledR} 85$ as surfactant stabiliser at a concentration of $5 \% w / v$ in hexane [57].

A phenazopyridine-phthalimide nano-cocrystal suspension was produced by dissolving $213 \mathrm{mg}$ phenazopyridine and $147 \mathrm{mg}$ phthalimide in $2 \mathrm{~mL}$ of dimethyl sulfoxide (DMSO) separately, after which the individual solutions were rapidly injected into $50 \mathrm{~mL}$ $0.4 \% w / v$ SDS aqueous solution at approximately $2{ }^{\circ} \mathrm{C}$ using ultrasonic conditions resulting in the formation of a NCC suspension after 15-30 s [58].

Liu et al. [59] produced NCC using top-down and bottom-up approaches. NCC produced using a solution approach were obtained by dissolving $311 \mathrm{mg}$ myricetin and $402 \mathrm{mg}$ nicotinamide separately in $7 \mathrm{~mL}$ and $3 \mathrm{~mL}$ methanol, respectively [59]. The solutions were rapidly injected together into a conical flask at $0{ }^{\circ} \mathrm{C}$ and sonicated for $30 \mathrm{~min}$ using an ultrasonic processor set at a frequency of $40 \mathrm{kHz}$ with a power output of $50 \mathrm{~W}$ following which the low-temperature control was stopped but ultrasonic agitation maintained. The resultant precipitate was removed after 10, 20, and $30 \mathrm{~min}$, filtered and dried for $24 \mathrm{~h}$ at $25{ }^{\circ} \mathrm{C}[60]$.

Witika et al. reported the synthesis of lamivudine and zidovudine NCC using a bottom-up technique [19,42]. The NCC were manufactured using a pseudo one solvent cold sonochemical synthesis technique [19,42]. The individual components were dissolved in methanol and water and injected into a precooled conical flask and sonicated. 


\section{Nucleation and Crystal Growth}

Supramolecular synthons are defined as structural units within super-molecules which can be formed and/or assembled by known synthetic operations involving intermolecular interactions. Supramolecular synthons are spatial arrangements of intermolecular interactions. Therefore, the overall goal of crystal engineering is to recognise and design synthons that are robust enough to be interchanged between network structures [9]. The Cambridge Structural Database may be used to identify stable hydrogen bonding motifs with the ambition that the most robust motifs will remain intact across a family of related structures $[61,62]$.

\subsection{Supramolecular Processes in Crystal Growth}

Nucleation is a molecular assembly process, where a critical number of molecules are needed to achieve a phase change from the liquid melt or solution to form a crystalline solid. The driving force for achieving the critical point of molecular assembly is linked to the free energy of the process [6]. For solution-based crystallisation, which is predominantly used in processing API, the free energy required is linked to the solubility behaviour of the material in a specific solvent. The magnitude of the difference in solubility exhibited by the molecules that are crystallising from a completely solubilised state at a specified composition and temperature drives the process. The larger the differential between solubilised state and the equilibrium state, the greater the supersaturation. The resultant growth of a crystal is dependent on the solubility behaviour and any competing nucleation, which may also be taking place because of the degree of supersaturation achieved. It is, therefore, this phase change process that distinguishes crystallisation from dissolution $[63,64]$.

\subsection{Crystal Habit, Morphology, and Growth}

Once nucleation has been achieved, crystal growth dominates and is the process, which leads to the evolution of embryonic crystals into a crystal form of defined size and shape. The key drivers with regard to the shape of the growing crystal are related to the crystal lattice of molecular solids and the effects of the choice of solvent and additives on the process of crystal growth. As such, crystal growth is a layer-by-layer process, with the evolution of layers being defined by crystal packing of the unit cell. The unit cell, in turn, describes the critical elements of how a specific molecular species has been assembled in the crystalline state in three-dimension $[6,65]$.

\section{Techniques used in the Physicochemical Characterisations of NCM}

The characterization approaches for NCM are a combination of techniques used to determine crystallinity, particle size, particle size distribution, as well as intra- and intermolecular interactions. In addition, beneficial characterization of NCM with regard to chemical composition is often required. Broadly, the characterization of NCM, much like any other nanometric drug delivery systems, can be classified into in vitro and in vivo categories [66].

To understand the potential performance of NCM in vivo, physicochemical characterisations need to be carried out, followed by cell-culture studies. The physicochemical characterisations offer an understanding of how the NCM will perform prior to cell testing [67]. These are often conducted "in-glass". Cellular testing is less ethically ambiguous, is easier to control and reproduce, and is less expensive when compared to animal testing [68]. Once a proof of concept for NCM has been demonstrated in vitro, safety and therapeutic efficacy are then tested in animal models. The results of animal studies play a fundamental role in decision-making with regard to progression towards clinical trials. An animal model that reflects the pathophysiology of human disease is invaluable when predicting therapeutic outcomes in humans [66,69].

A collection of recommendations pertaining to nanomaterial characterization reviewed a consensus on a large number of nanomaterial properties [67]. A condensed list of physicochemical parameters for the risk assessment of nanomaterials was compiled based 
on this collection and we concluded that the nanomaterial properties that are listed in at least half of the 28 sources analysed were [67];

- Specific surface area

- Particle size

- Particle size distribution or polydispersity index

- Crystallinity

- Surface Reactivity

- Solubility

- Agglomeration

- Surface charge

- Elemental/molecular composition

- Surface chemistry

In this review, we will use this list to correlate characterization procedures to the properties on the list.

\subsection{Dynamic Light Scattering (DLS)}

Dynamic light scattering (DLS) is commonly used for particle size determination and measures the Brownian motion of particles in suspension by relating velocity, known as the translational diffusion coefficient, to the size of particles according to the Stokes-Einstein equation $[70,71]$.

\subsubsection{Particles Size (PS)}

Particle size (PS) investigations serve as one of the main determining factors of biodistribution and retention of NCM in target tissues. PS is defined as the size of a hypothetical hard sphere that exhibits the same diffusion characteristics as the NCM being measured. The result is reported as mean particle size and homogeneity of size distribution. The latter parameter is expressed as the polydispersity index (PDI), which is a dimensionless parameter calculated from cumulative analysis of the DLS-measured intensity autocorrelation function [71]. A PDI value in the range $<0.25$ indicates a desirable homogeneity whereas a PDI value $>0.5$ indicates heterogeneous particle sizes [72]. While DLS provides a simple and rapid estimate of particle size, several studies suggest that DLS exhibits inherent limitations and is relatively poor at analysing multimodal particle size distributions [72,73].

By way of example, when a mixture of $20-$ and $100-\mathrm{nm}$ nanometre particles are measured, the signal for the small particles may be lost because the signal intensity of a spherical particle of radius $r$ is proportional to $r$ [74]. Therefore, the scattering intensity of small particles tends to be masked by that of larger particles. Microscopy provides an accurate assessment of the size and shape of a NCM but often requires complicated sample preparation steps specific to the microscopic technique used [73], which in turn may change samples and create artefacts such as NCM agglomeration, which is particularly observed during drying prior to electron microscopy [75]. Furthermore, due to the limited throughput capability, it is difficult to obtain an accurate particle size distribution [74], and the underlying principle is that the sample status in each method is not the same.

\subsubsection{Surface Charge}

Surface charges, expressed as the Zeta Potential (ZP), critically influences the interaction of NCM with the dispersion media [72]. The ZP is commonly measured using Laser Doppler Electrophoresis (LDE), which evaluates the electrophoretic mobility of suspended NCM in a dispersion medium. It is a measure of the energy potential at the boundary of the outer layer. It is generally accepted that NCM that possess a ZP more positive than +30 $\mathrm{mV}$ or more negative than $-30 \mathrm{mV}$ exhibit colloidal stability that is maintained by repulsion due to electrostatics. Much like with PS measurements, heterogenous samples have misleading $\mathrm{ZP}$ measurements due to the $\mathrm{ZP}$ of larger particles dominating the scattering signal to the detriment of smaller particles [76]. The measurement of the $\mathrm{ZP}$ is, in part, dependent on the ionic strength and valency in an NCM dispersion. High ionic strength 
and valency ions compress the electric double layer, resulting in a reduced $\mathrm{ZP}$. The $\mathrm{pH}$ also has a significant influence on $\mathrm{ZP}$ and in alkaline suspensions, the NCM acquire a negative charge and vice versa. Therefore, $\mathrm{ZP}$ should be reported with a corresponding $\mathrm{pH}$ at which the measurement was taken [70]. Additionally, it is recommended that information of the suspension be precisely described when reporting the $\mathrm{ZP}$, including the ionic strength, composition of the dispersion medium, and $\mathrm{pH}[77,78]$. However, the $\mathrm{ZP}$ is of little consequence if the NCM is stored as a solid intended to be redispersed prior to use.

\subsection{Thermal Analysis}

NCM exhibit many unique properties, which are often superior to those of coarsegrained materials. Consequently, NCM offer significant potential for use in a variety of pharmaceutical applications. Solidification of nanosuspensions of NCM has been identified as a tool to increase patient acceptance/adherence and long-term stability [79].

Due to a high-volume fraction of grain boundaries, NCM have the intrinsic shortcoming of poor thermal stability that significantly limits their use. To aid in understanding this drawback, thermal stability has become a significant aspect in the field of pharmaceutical NCM research [80]. It is therefore of utmost importance to conduct thermal analyses on NCM to determine their suitability in potential secondary or downstream pharmaceutical applications.

\subsubsection{Thermal Gravimetric Analysis (TGA)}

TGA is one of the oldest thermal analytical procedures and has been used extensively in the study of material science. The technique monitors changes in sample weight, usually nitrogen, as a function of temperature. TGA can be used to facilitate the assessment of processing temperatures of thermally based secondary manufacturing processes such as hot-melt extrusion while also finding utility in determining the presence of residual solvents or moisture. When used as a pre-formulation tool for hot-melt extrusion, TGA is used to determine the thermal stability of the polymers and nanocrystalline API. It allows for the determination of a range of operating temperatures in hot-melt extrusion. This is done in order to avert thermal degradation that may occur during the manufacturing process. TGA can also be used to determine the moisture or residual solvent contents as well as the presence of a solvate in NCM, especially in the instances where a crystallization step was part of the synthetic process of a given NCM.

\subsubsection{Differential Scanning Calorimetry (DSC)}

DSC is a thermal analytical technique that provides qualitative and quantitative information as a function of time and temperature in respect of thermal changes in materials that involve endothermic or exothermic processes, or changes in heat capacity [81].

DSC is used for the determination of melting point, glass transition temperature, and purity of samples. When applied to NCM products, it is useful in determining changes in crystallinity, glass transition of stabilizing material, and the presence of more than one polymorphic form of the API. This is especially important for API that occurs in different polymorphic forms. Moreover, some top-down techniques like HPH can lead to a batch with an amorphous fraction. This, in turn, could lead to a significant increase in saturation solubility. The DSC of a pure drug, a physical mixture of drug and excipients (stabilizer), and the final formulation, which may be in dried form, is routinely done as pre-formulation and post-formulation quality tests [82].

Kocbek et al. prepared Pluronic ${ }^{\circledR} 68$ stabilized ibuprofen nanosuspensions. The study results indicated the formation of a eutectic mixture of the drug and Pluronic ${ }^{\circledR} 68$. In this case, DSC revealed a lower temperature melting peak representing the melting of the eutectic system, and a second peak representing the melting of the excess ibuprofen. Based on the position of the second peak, it was estimated that ibuprofen was in excess after eutectic formation [83]. 
Similarly, DSC was used to investigate the changes in the crystallinity of itraconazole (ITR) after the nanoprecipitation and drying processes or possible interactions between the API and excipients [84]. The results obtained indicated a small change in melting temperature of ITR, which were attributable to the reduction in PS and were deemed to not have been a consequence of CPP. The results also showed the presence of an amorphous component of ITR and confirmed the presence of both crystalline and amorphous ITR [84].

Although DSC cannot be used to establish the chemical nature of a sample being tested, the results can be useful for determining whether samples exhibit different thermal properties and can therefore distinguish differences relating to material identity, specific solid-state forms, and/or purity [85].

\subsection{X-Ray Techniques}

$X$-ray diffraction (XRD) is one of the most widely used techniques for the characterization of NCM. Ideally, crystalline structure, phase behaviour, lattice parameters, and crystallite grain size are derived from XRD [86]. Crystallite grain size is determined using the Scherrer equation [87]. It utilizes the diffractogram of the sample by analysing the broadening of the peaks of the highest intensity. XRD has the advantage of resulting in volume-averaged values while being statistically representative. Despite its applicability, $\mathrm{XRD}$ is often replaced in use by single-crystal X-ray diffraction (ScXRD) as the latter is a more definitive technique for determining three-dimensional crystal lattice structures. ScXRD provides an accurate representation of atomic coordinates and thermal parameters. These are obtained by using parameters such as molecular geometry and intermolecular distances [88]. ScXRD does have a major disadvantage in that it requires the accessibility of a single crystal. Unfortunately, in many instances, polycrystallites are formed, especially when using the top-down methods. In such cases, powder X-ray diffraction (PXRD) is the obvious alternative to ScXRD [88].

X-ray photon spectroscopy (XPS) capitalizes on the photoelectric effect [89]. In XPS, following adsorption of incident photons from an $\mathrm{X}$-ray source, core electrons are emitted from a sample and the kinetic energy determined by conservation of energy. As a result of inelastic processes from scattering deep in the bulk, only surface electrons escape without energy loss. Identification of specific elements is accomplished on the basis that each element has a characteristic set of binding energies. The concentration of the element directly correlates to the number of photoelectrons and as such, after background removal, peak areas can be used as a means to quantify specific elements [89].

\subsubsection{Powder X-ray Diffraction (PXRD)}

PXRD is a non-destructive analytical technique used for the measurement of crystalline and non-crystalline materials. It is utilized to collect structural data at the anatomic level to understand phase transitions, determine the degree of crystallinity, and identify polymorphic and solvatomorphic phases [90,91]. It is an essential tool in pharmaceutical research as it can be applied to polycrystalline materials in both solid and liquid forms. It has application in all stages of drug development, production, and quality control testing of API, excipients, and final products [90,91]. It is an easy-to-use technique, yields reliable and reproducible results and is relatively inexpensive. Moreover, it is highly sensitive and has applications in both qualitative and quantitative analyses [90].

PXRD is more difficult to use to determine the crystal morphology or habit of an API and excipients, and to investigate crystal morphology changes while these substances maintain crystallinity [92]. Peak broadening for particles below $3 \mathrm{~nm}$ in size coupled with non-suitability for amorphous materials are the main drawbacks of this technique [86]. In research conducted by Upadhyay et al., the PS of magnetite nanoparticles were determined using X-ray line broadening. The broadening of XRD peaks was mainly caused by particle/crystallite size and lattice strains other than instrumental broadening [93]. 
Similarly, Li et al. used XRD and noticed that after preparing copper telluride nanostructures with different shapes (i.e., cubes, plates, and rods), the relative intensities between the different XRD peaks varied in relation to the particle shape [94].

The XRD-derived size is often larger than magnetic size. This is due to smaller domains being present in a particle where all moments are aligned in the same direction, even if the particle is a single domain. Consequently, the use of microscopy is often preferred for size determination over XRD [95].

\subsubsection{Small Angle X-ray Scattering (SAXS)}

For nanomaterials, SAXS is usually the best choice because below a certain particle size, PXRD is not sufficiently sensitive and the $\mathrm{X}$-rays are scattered in an amorphous halo.

SAXS can be used to elucidate the PS, PDI, and morphology [86]. With regards to PS, more statistically reliable results are obtained with SAXS when compared to transmission electron microscopy (TEM). SAXS has been used successfully to study the structural changes of platinum $(\mathrm{Pt})$ nanoparticles $(\mathrm{NP})$ with changes in temperature [96]. The size obtained by XRD was different from the corresponding SAXS value at certain temperatures. This is because XRD is susceptible to the size of the long-range order region while SAXS is susceptible to the size of the fluctuation region of electronic density [86]. In these experiments, it was observed that the PS obtained with SAXS were slightly larger than those obtained using TEM. The reason is that $\mathrm{Pt} \mathrm{NP}$ were coated with polyvinyl pyrrolidone (PVP) and the scattering intensity due to the PVP coating could not be easily removed [96].

Cipolla et al. used to SAXS to determine the PS, shape, and asymmetry of liposomes loaded with NC $[97,98]$. As part of the study outcomes, SAXS was identified as a useful and versatile technique to study the solid state of $\mathrm{NC}$ loaded in liposomes and dispersions, as well as to study the behaviour of drug NC in dispersion as a variable of temperature and $\mathrm{pH}[98]$.

SAXS has also found use in the solid-state characterization of doxorubicin sulphate nanocrystal loaded liposomal dispersions $[99,100]$.

It has to be noted that SAXS is a low-resolution technique and in certain cases, further studies by XRD and/or electron diffraction techniques are indispensable for the characterization of NCM.

\subsubsection{X-Ray Photon Spectroscopy (XPS)}

Due to its ability to determine surface elemental composition and by virtue of being non-destructive, XPS has become a key characterization technique for NCM [101]. It can be utilized to provide detailed and qualitative information on chemical elements present on the surface of materials. This is particularly useful for NCM stabilized by polymers and/or surfactants. [102]. Recent advances utilizing special sample cells permits the use of liquid samples and consequently broadens the application of XPS [103], specifically for dispersed NCM.

Due to the nature of NCM, XPS has taken on more significance in the advancement of pharmaceutical nanotechnological applications by being capable of detecting the presence and determining the relative concentrations of elements while also determining the average thickness of surface coatings in NCM. As such, it is a useful technique for analysis of potential adulteration or impurities arising during nanomaterial synthesis and/or handling [89].

Through XPS, Qiu et al. conducted an investigation into the difference in reduction behaviour between nanocrystalline and microcrystalline ceria after $\mathrm{Ar}^{+}$bombardment or X-ray irradiation. Despite identical experimental conditions, viz. pellets compacted by uniaxial pressure of $10 \mathrm{MPa}$ and XPS data being recorded before and after bombardment experiments, it was observed that the reduction levels of $\mathrm{Ce}^{4+}$ to $\mathrm{Ce}^{3+}$ were lower in nanocrystalline than microcrystalline ceria [104]. 
Chow et al. used XPS to ascertain drug encapsulation and demonstrated that most of the drug was entrapped within the cores of NPs, and that the particle composition of the surface was mainly the adsorbed co-stabilizer and polyethylene glycol (PEG) block [105].

Similarly, Dong et al. used XPS to prove the predominant presence of the PEG shell on the surface of paclitaxel loaded methoxy poly(ethylene glycol)-poly(lactide) (mPEG-PLA) NP [106].

In a study to analyze the external surface of a novel controlled release formulation for the anticancer drug paclitaxel (Taxol ${ }^{\circledR}$ ) loaded in PLGA nanoparticles and stabilized by $\alpha$-tocopheryl polyethylene glycol succinate 1000 using XPS, it is determined that the outermost layer was composed by a majority of TPGS 1000 molecules [107].

\subsection{Vibrational Spectroscopy}

\subsubsection{Fourier Transform Infrared (FTIR) Spectroscopy}

FTIR spectroscopy is used for the physical and chemical characterization of powder mixtures in the solid state by evaluating functional groups, identifying bond formation, and comparing bond formation [108,109]. It is a fundamental approach for the study of API-excipient interactions since it permits rapid and simple elucidation of chemical and structural attributes of organic materials as it is sensitive to molecular vibrations that are specific for specific functional groups [108]. Molecular vibrations are categorized based on the energy related to the functional groups within molecules over the $650-4000 \mathrm{~cm}^{-1}$ wavenumber range [109].

FTIR is mostly used to identify the purity of drug compounds in the crystal, to ascertain the polymorph in the NCM, and some cases are used to determine whether a solvate form of the NCM is present. FTIR can be of specific use in the determination of polymorphic changes during the nanosizing process. For instance, during HPH, piroxicam demonstrated to undergo polymorphic transformation [110]. The piroxicam nanocrystals were stabilized using poloxamer 188. FTIR was used in conjunction with other characterization techniques and confirmed that the crystalline form I of piroxicam made up the majority of the unprocessed piroxicam. A change of colour from white to yellow following $\mathrm{HPH}$ indicated a polymorphic conversion from form I to form III and the monohydrate. Confirmation using XRD, FTIR, and DSC confirmed that NC were a mixture of form III and the monohydrate [110].

Lamivudine-zidovudine NCC were synthesized with or without stabilizer $[19,111]$. The NCC formulation was stabilized with different stabilizers including SDS, TPGS 1000, Tween ${ }^{\circledR} 80$, and Span $^{\circledR}$ 80. The FTIR spectrum of the NCC was compared to those of the individual drug compounds to verify the absence of chemical interactions. The FTIR spectrum of the NCC revealed the presence of a monohydrate with the presence of a water peak without any peaks corresponding to the API $[19,111]$.

FTIR was used to identify polymorphic changes in wet-milling using an HPH for an experimental anti-cancer compound, SN 30191. The process-induced transformations were studied as a function of time and pressure using infrared spectroscopy, and it was determined that conversion from form II to form I was pressure-dependent [112].

\subsubsection{Raman Spectroscopy (RS)}

RS is a versatile analytical technique that can be used in drug and formulation development, process control, as well as post-sale analyses [88]. Multivariate data analysis techniques are valuable for opening spectra to interpretation, allowing quantification of compounds, and simplification of large spectral data sets. In the pharmaceutical industry, multivariate techniques, such as partial least squares (PLS) analysis has permitted compounds or properties of compounds to be quantified. API quantification and the ability to determine interactions between API and excipients are examples of this [88].

RS can be used as a tool to identify the phases and phase transitions of various NCM, determine which regions of a nanomaterial are amorphous or crystalline [113-115], whether there are any defects present in the nanomaterial, determine the size (diameter, lateral 
dimensions, etc.) of various types of nanomaterials [116,117], whether the nanomaterial is homogenous or whether a dispersion of nanoparticles is uniform in size, determine the shape of nanomaterials (rod, spherical, etc.), and differentiate between different allotropes of the same material [118].

Spironolactone NC were synthesized with different stabilizers including poloxamers 407 and 188, hydroxypropyl methylcellulose (HPMC), and sodium deoxycholate. Preformulation and post-formulation experiments using RS to compare the drug nanosuspensions and raw materials were used. Peak shifts were not observed in spironolactone NC stabilised with poloxamer 188, HPMC, and sodium deoxycholate. However, the Raman spectra revealed API peak disappearance with poloxamer 407 stabilized NC, indicating that interactions between drug and stabiliser had occurred in that case [119].

A novel bottom-up process to fabricate fenofibrate NCM termed as "controlled crystallization during freeze-drying" (CCDF) was used to synthesize NC. The size of the NC in this process was influenced by various factors including the freezing rate. To determine the stage at which solute crystallisation occurred, RS monitoring was used. The in-line Raman measurements showed that the first two steps, the freezing step, and the crystallization step are critical steps that determined the final size of the fenofibrate crystals [120].

\subsection{Microscopy Techniques}

Microscopy imaging is extremely useful when examining the size, shape, and detailed morphology of particles, and for understanding morphology-related properties of substances, formulations, and/or dosage forms [121]. The techniques are frequently used in research and development, especially for solid dosage forms while only a limited number of examples are referenced here. In the evaluation of pharmaceutical raw materials such as API and excipients, microscopy images reveal the size, shape, and morphology of particles, which helps in understanding some processing properties and the pharmaceutical performance of these materials $[122,123]$. The impact of different preparation procedures, such as precipitation or milling methods, on important properties (shape, size, chemical composition) of the resulting API or excipient particles in NCM can be investigated using microscopy [124-127].

\subsubsection{Scanning Electron Microscopy (SEM)}

SEM is an analytical technique used for the characterization of surface morphology of API and excipients microscopically, in particular, differences in crystal habits and the shape of the samples $[128,129]$. SEM does not convey any information in respect of the chemical structure and/or thermal behaviour of compounds, and is used with other thermal and spectroscopic methods such as DSC, TGA, and FTIR to identify incompatibilities between API and excipients [129].

\subsubsection{Scanning Electron Microscopy Energy Dispersive X-ray Spectroscopy (SEM-EDX)}

Investigation of a sample by SEM does not only produce images but may also provide specific information in respect of the chemical composition of a sample at specific locations in the sample. Energy-dispersive X-ray spectrometry (EDX) is based on the generation of $X$-rays following the interaction of an electron beam with the atoms in a sample. SEM-EDX has potential applications in NC and NCC use particularly in determining contamination that could arise from milling media. EDX has been successfully used for this application. EDX can also be used to surmise the overall presence of coating agents through determining the presence of coating agent-specific atoms or by observing an increase or reduction in atomic \% of pure drug elemental components. EDX was specifically used for both of these applications for the determination of the presence of TPGS 1000 and SDS in NC prepared using the bottom-up method, and the presence of chromium and iron contamination from the steel media milling media during the top-down manufacture of lamivudine-zidovudine NCC [42,111]. 


\subsubsection{Transmission Electron Microscopy (TEM)}

Conventional transmission electron microscopes are electron-optical instruments analogous to light microscopes [130]. The main difference being that in TEM, the illumination of the specimen is by an electron beam as opposed to light. An increase in acceleration voltage of the electrons directly results in an increase in resolution. However, a reduction in contrast results from increasing acceleration voltage as a consequence of the scattering of the electrons being decreased at higher velocity [131].

TEM is particularly useful for the study of colloidal and nanostructured drug delivery systems including NCM $[88,132]$. Much like SEM, TEM is more useful in determining surface morphology, differences in crystal habit, and determining particle shape. TEM is widely the most applied method for evaluation, is used in many characterisation approaches, and is considered the gold standard for PS determination.

\subsection{Quantitative Techniques}

4.6.1. (Ultra) High-Performance Liquid Chromatography ((U)HPLC)

During different stages of pharmaceutical development, including synthesis and isolation of API, dosage form development, and pharmacological testing, gas or liquid chromatographic methods of analysis are used for quantitative and/or qualitative purposes [133].

High-Performance Liquid Chromatography (HPLC) is based on the principles and theories of gas chromatography and is a rapid and efficient analytical procedure $[134,135]$. In the broadest sense, chromatographic separations can be classified as normal (NPC) and reversed-phase (RPC), where the stationary phase is more polar than the mobile phase for NPC, whereas the converse is true for RPC [136].

RP-HPLC is the method of choice for in vitro analysis of API due to the stability and reproducibility of stationary phases used for analyses [137]. A large number of aqueous components in the mobile phase, in addition to the ease of reproducing analytical methods in different laboratory settings, make RP-HPLC an ideal analytical method for product development and quality control purposes in the pharmaceutical industry [137].

The use of stationary phases that have a silica-based backbone chemically bonded to a variety of different organic functional groups, form the basis for separations in RPHPLC [138]. Separation is achieved when the sample to be analysed partitions between an organic modifier used in the mobile phase and the stationary phase or column $[139,140]$. In general, non-polar compounds are attracted to hydrophobic stationary phases and polar compounds preferentially partition into polar mobile phase components [139]. The specificity and selectivity of an analytical method is the consequence of interaction(s) between analyte(s) and binding sites of the stationary phase and partitioning in the mobile phase [141]. Silica-based columns with $\mathrm{C}_{3}, \mathrm{C}_{4}, \mathrm{C}_{8}$, or $\mathrm{C}_{18}$ alkyl chains bonded to the backbone are the commonly used non-polar stationary phases in RP-HPLC. Silica-based phases are compatible, do not swell in water, and some organic solvents are, therefore, suitable for use with mobile phases comprised of these solvents [139,141,142].

The mobile phase in RP-HPLC is usually water or a buffered solution with an organic modifier such as methanol or acetonitrile added to the composition in order to reduce the polarity of the mobile phase, thereby facilitating the achievement of appropriate retention characteristics for the compounds of interest [138]. Other factors that affect the retention time of analytes include temperature, $\mathrm{pH}$ of the buffer and/or mobile phase, stationary phase properties, polarity of the mobile phase, flow rate, and mobile phase composition [139,140].

\subsubsection{Ultraviolet-Visible Spectrophotometry (UV-Vis Spec)}

Spectroscopy is a branch of science which deals with the study of electromagnetic radiation and its interaction with matter. The UV-visible spectrophotometry specifically is one of the most often used analytical techniques in the pharmaceutical industry [143,144]. The technique is used to evaluate the concentration of a given organic or biological com- 
pound $[145,146]$. This process is achieved using UV or visible radiations which are absorbed by a substance in solution [143-145]. The ratio or function of the ratio of the intensity of two beams of light in the UV-vis region is measured by instruments known as UV spectrophotometers [144]. Absorption of radiation of a specific wavelength, $\lambda$, is an indication of the presence of one or more chromophores [147]. A chromophore is a molecular group that has a pi, $\pi$, bond which when inserted into a saturated hydrocarbon, produces a compound with absorption between $185 \mathrm{~nm}$ and $1000 \mathrm{~nm}$ [148]. Temperature and $\mathrm{pH}$ may also cause changes in both the intensity and the $\lambda$ of the absorbance maxima $[149,150]$.

Analysis of compounds using spectroscopy is governed by the Beer-Lambert law [144]. Beer's law states that the intensity of a beam of parallel monochromatic radiation decreases exponentially with the number of absorbing molecules [144,151-153]. Thus, according to Beer, the concentration of a compound is proportional to the absorbance produced [144,150]. Lambert's law states that the intensity of a beam of parallel monochromatic radiation decreases exponentially as it passes through a medium of homogenous thickness [152,154]. As both laws deal with the intensity of monochromatic radiation, a combination of the two laws has been used to yield the Beer-Lambert law [144,151-154].

Different NCM manufacturing methods and conditions have an influence on the solid state form while environmental conditions affect the thermodynamic stability of the polymorphic form [155]. PXRD, DSC, SEM, FTIR, and RS are the most commonly used methods to establish and monitor the solid-state forms of NCM. The use of microscopy techniques is the mainstay of PS, particle shape, and morphology determination. A summary of techniques and their applications is depicted in Table 1.

Table 1. Characterizations associated with NCM (Adapted from [86]).

\begin{tabular}{cc}
\hline Entity to Be Characterized & Techniques * \\
\hline Size and morphology & DLS, SEM, TEM \\
Surface charge & ZP \\
Surface chemical analysis & XPS, EDX \\
Crystal structure & SAXS, PXRD, DSC \\
Growth kinetics & SAXS, NMR, TEM, cryo-TEM, liquid-TEM \\
Agglomeration state & ZP, DLS, DCS, UV-Vis, SEM, Cryo-TEM, TEM \\
composition & XPS, FTIR, NMR, \\
Ligand binding/density/mass/surface & TEM, SEM \\
/ bulk composition & (U)HPLC, UV \\
Dispersion of NCM in matrices/supports & \\
Dissolution Testing & * Physical state of samples: DLS, ZP, TEM, UV-Vis, NMR, and HPLC; liquid state. All other techniques; solid state.
\end{tabular}

\section{Applications of Characterization Techniques on Prediction of NCM Performance 5.1. Prediction of Physical and Chemical Stability of NCM}

The success of API delivery to target tissues is largely dependent on the maintenance of stability by the NCM in systemic circulation. The fate of NCM, in vivo, is in part determined by the ability to retain size and payload external to target tissues and to release API to the cells at predetermined rates in appropriate quantities. Ideally, a nanometric drug carrier must remain stable by resisting aggregation or degradation while maintaining API concentrations in the blood until it reaches the target site(s). Altered biodistribution as well as premature drug release can occur as a result of NCM instability, subsequently compromising the performance and efficacy of the delivery system. As such, it is of utmost importance to evaluate NCM with regards to estimating the success of the drug delivery system.

It is important to conduct a series of in vitro tests to investigate the stability of NCM in different biologically relevant media. It is ultimately desirable to conduct investigations into the stability of NCM in vivo since these techniques provide reasonable assessments and prediction of the likely stability of the formulation in physiological environments. 


\subsubsection{Suspension Stability}

The main role of stabilizers in NCM synthesis is to prevent the growth of crystals resulting in micro or macroparticles. However, most stabilizers may offer "stealth" properties, enhance permeation, prevent efflux, enhance cell-targeting, or prevent clearance. By careful formulation, the dissolution and stability can be enhanced while also improving permeation. Consequently performance may be altered by the selection of stabilizers as part of the critical formulation parameters (CFP) [156].

The majority of stabilizing agents are amphiphilic moieties that have the ability to adsorb to the surfaces of newly formed drug particles by utilizing hydrophilic-hydrophobic interactions. This results in an enhancement in the wetting of NC or NCC [155]. In its most classical form, the DLVO theory describes nanoparticle stabilization based on steric and/or electrostatic interactions. Steric stabilization, by use of polymers or non-ionic surfactants, has been more commonly utilized, and has an added facet of being temperature sensitive. Conversely, electrostatic stabilization is achieved with ionic polymers or surfactants. In systems where stabilization is achieved only by electrostatic forces, the ZP should be higher than $|30| \mathrm{mV}$. As previously stated, this value is vulnerable to changes in $\mathrm{pH}$, the presence of ionic species, and changes in hydration (drying) [155].

The physical stability of NCM is usually predicted in the suspension state by the value of the ZP [76]. The use of ZP as a predictor of stability has been shown to be applicable in nano-formulations containing nevirapine [157], efavirenz [158], and curcumin [105]. More specifically, NCM nanosuspensions of miconazole [159], indomethacin [160], and ascorbyl palmitate [161] exhibited ZP-dependent stability.

\subsubsection{Phase Behaviour}

For crystal cell units, it is important to confirm that the API exists, and in the case of NCC, co-former exist as a co-crystal by non-ionic interaction using appropriate analytical techniques [162]. Furthermore, the extent of polymorphism must be considered when determining the stability of a system and attempting to predict API release from that system.

The most frequently used techniques for investigating the phase behavior of NCM include the use of DSC, TGA, PXRD, and ScXRD. By investigating the thermal behavior and crystallinity of such systems, valuable complementary information can be generated for the characterization and quality control of NCM formulations and technologies [163].

Modulated temperature DSC (MTDSC) is sensitive and has a high separation capacity with overlapping thermal events as quasi-static material properties, and frequency dependency of thermal events are monitored, whereas TGA measures sample mass during the heating process and is convenient for determining the presence of solvates and hydrates [163].

\subsubsection{Determination of Critical Aggregation or Micelle Concentration}

The critical micelle concentration (CMC) can be used as a measure of the stability of self-assembling NC or NCC systems including polymeric or surfactant stabilized NCM systems. The CMC is defined as the concentration at which self-assembled particles may form. This is a quantitative measure of the physical stability of NCM in solution. A relatively low $\mathrm{CMC}$ is indicative of more stable NCM systems than those in which a high CMC is likely. In other words, NCM prepared using stabilizers with a low CMC are more likely to maintain state as a consequence of dilution in the blood [164-168].

\subsubsection{Chemical Degradation Analysis}

The most standard approach to monitor and/or detect chemical degradation is analysis using (U)HPLC. Impurities or degradation products often present as new peaks; however, recognition of additional products often requires the use of techniques such as liquid chromatography-mass spectrometry (LC-MS). Degradation of molecules can be induced using harsh processing conditions, and exact knowledge of the chemistry of 
unwanted products is crucial in order to recognize and avoid potentially problematic process steps [163].

Vibrational spectroscopic methods may also be used to determine whether a chemical change has taken place during the process of manufacture and storage. The disappearance of peaks associated with key frequencies of the API could be an indication of degradation. FTIR and RS have been used to ascertain that NCM formulated for the delivery of lamivudine-zidovudine [19,42,111], tadalafil [169], and diclofenac [170] had not undergone chemical degradation or chemically interacted with the stabilizers.

While less commonly used for the purposes of determination chemical degradation, SEM-EDX may offer valuable information regarding the state of the NCM within a bulk. The technique was effectively used to determine whether chemical degradation had occurred by revealing the disappearance of elemental peaks of the appearance of new ones. In addition, the percentage of abundance was equally used as a determinant of chemical degradation for the NCM [42].

\subsection{In Vitro Dissolution and Kinetics of Drug Release}

When NCM is used for delivery of API, the release of the API is evaluated over time in order to determine the availability of API for absorption and ultimately at target sites thereby influencing therapeutic outcomes [72]. Three possible mechanisms of release from NCM can be envisaged viz., desorption of adsorbed API (A), API diffusion from a polymer/surfactant matrix (B), and/or release following polymer/surfactant erosion (C) as depicted in Figure 1.

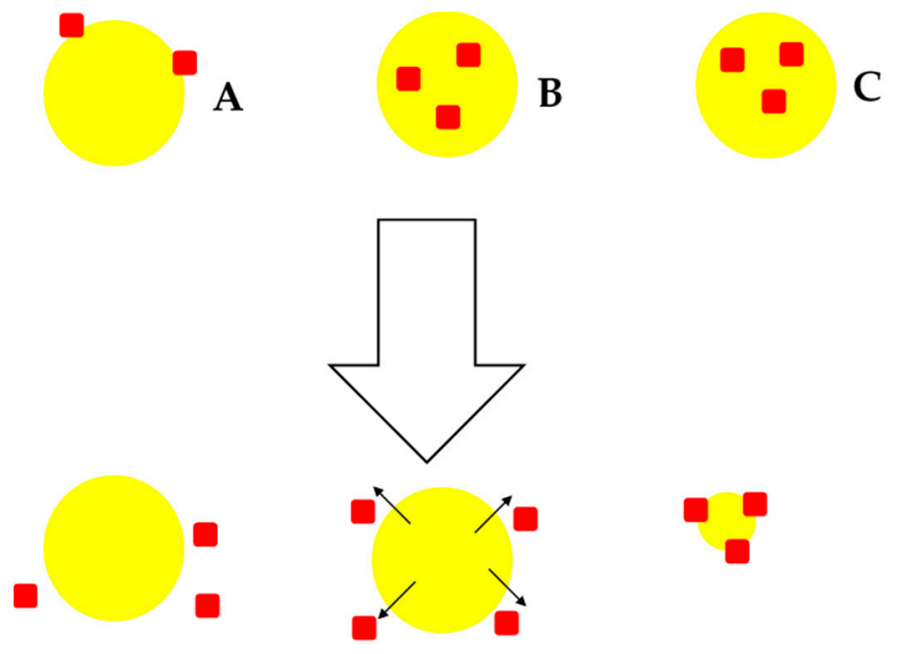

Figure 1. Possible mechanisms of drug release from NCM; desorption-controlled drug release (A), diffusion-controlled drug release $(\mathbf{B})$ and erosion-controlled drug release $(\mathbf{C})$.

In the case of matrix-type polymer/surfactant NCM in which the crystalline API is uniformly distributed or embedded in the matrix, drug release would be predominantly controlled by diffusion through the matrix and/or erosion of the matrix. Depending on the API and matrix physicochemical properties, either one of these mechanisms can be the dominant one. If diffusion occurs more rapidly than matrix/surfactant degradation, diffusion is likely to be the main mechanism of release. In many instances, an initial rapid initial release is noticed and attributable to the crystalline material fraction adsorbed or weakly bound to the surface(s) or that is not entirely embedded in the system (Figure 1A) [171].

API release from NCM is investigated in a number of ways. These are by dialysis membrane diffusion, membrane-less diffusion, sampling and separation, or the use of an in situ analytical technique [172]. When using the sampling and separation technique, API release is determined by separating the released API from the sample by filtration, 
centrifugation, or centrifugal filtration, and subsequent quantification using an appropriate analytical method such as (U)HPLC or UV spectroscopy.

The NCM are augmented with fresh release medium, preferably simulated bodily fluids and resuspended and incubated further until the next sampling interval. Despite this method having the capability of being performed with a small sample size and simple analytical equipment, several drawbacks exist: the separation methods is slow, tedious, and inefficient, making it inappropriate for studying rapid/immediate release NCM. In addition, the force of centrifugation or shear stress during filtration required for $\mathrm{NCM}$ separation tends to increase with a reduction in NCM PS. This can ultimately alter the release kinetics of the API. The main advantage of the dialysis membrane diffusion technique is that he diffusion of the NCM is continuous across the dialysis membrane and not subject to destructive separation processes, making sample acquisition simple and rapid $[163,173,174]$.

The use of dialysis membranes may attenuate API release as it is a diffusion barrier that may behave as an adsorptive surface. Thus, this approach should be conducted with control experiments in which free API is used to assess membrane effects. The dialysis membrane diffusion method typically makes use of large volumes of dissolution media. While large volumes maintain sink conditions for release, API analysis may be hindered due to the low concentrations to be tested. An in situ analytical technique is useful for studying NCM, which are prepared almost exclusively of an API. This technique is used to analyse the properties of NCM in situ to indirectly determine the quantity of API released. Various analytical techniques, including electrochemical analysis, solution calorimetry, or turbidometric and the light scattering techniques have been used for this purpose [172]. These approaches do not need separation of NCM and enable real-time assessment of the release kinetics of API.

While the aforementioned characterizations may be generally applicable, it may not always be applicable to use all of them. The role of PS, PDI, ZP, and polymorphism on NCM performance with regards to processability, content uniformity, and stability of a drug product is recognizable. The possible effect of PS and polymorphism on solubility, dissolution, and bioavailability parameters being strictly related to each other is one of the primary concerns. Definitions of specifications are required particularly when the product performance is affected by PS and polymorphism. We provide an appropriate decision tree in Figure 2, that is closely adapted to that in the ICH Q6A guidelines [175], on what characterization is required and to which performance parameter it relates. 


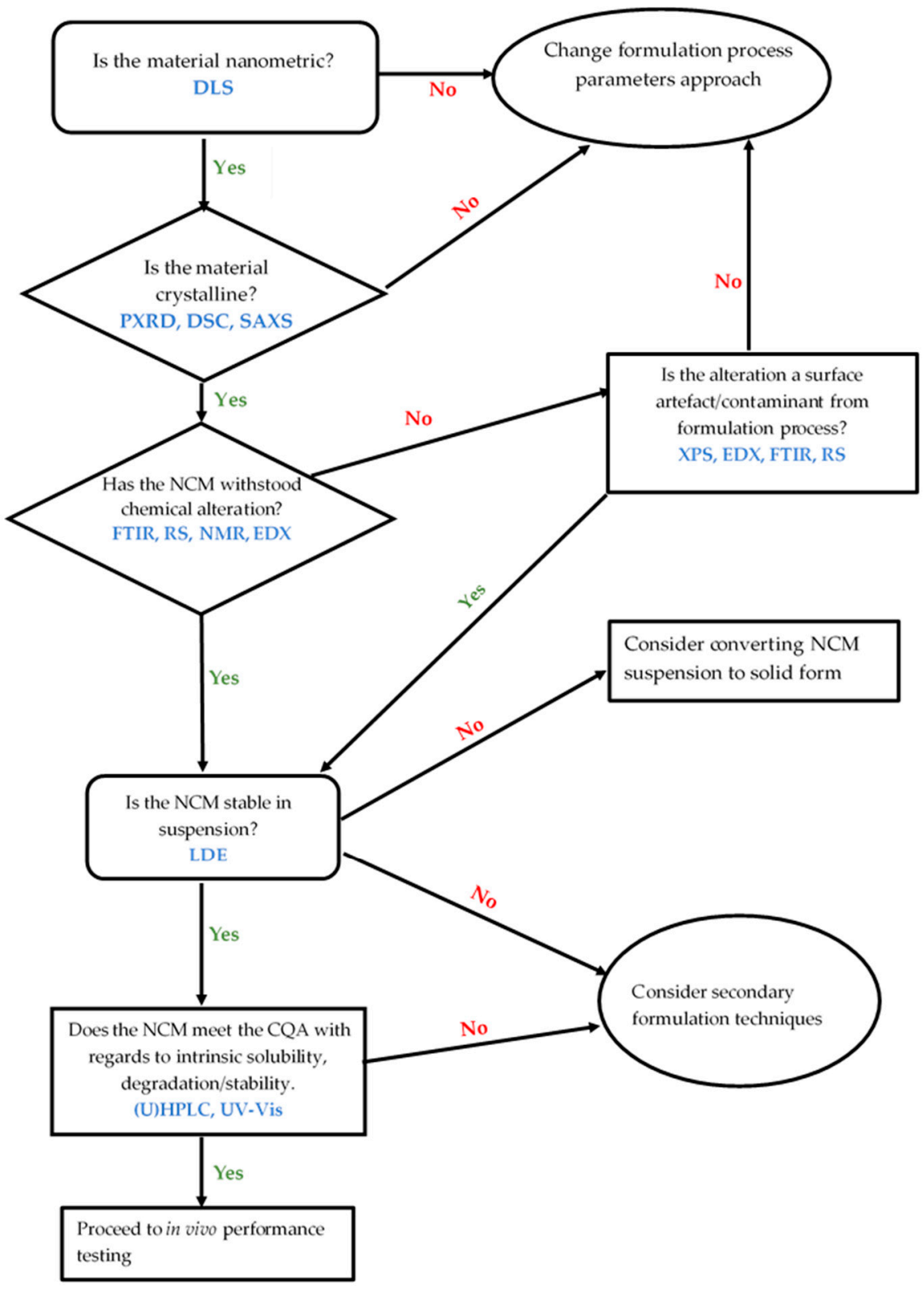

Figure 2. Decision tree relating to NCM characterization.

\section{Conclusions}

NCM are non-toxic crystalline carriers composed almost entirely of API and very little excipients.

Unlike other nanoparticle technologies such as solid lipid nanoparticles (SLN), nano lipid carriers (NLC), and nanocapsules, NCM are suitable for the delivery of hydrophilic and hydrophobic compounds with very high efficiency. NCM are also relatively easy to prepare and synthesize when compared to other nanoparticle technologies such as liposomes and nanocapsules that require multiple steps and use of organic solvents. NCM have the added advantage of exhibiting better stability than other nanoparticles due to the crystalline state of the particles. In addition, NCM formulations prevent the accumulation of the payload in cells and tissues of healthy organs and often exhibit improved bioavailability for some API. The suitability of the carriers has been proven since they are already on the market (Rapamune ${ }^{\circledR}$ and Emend ${ }^{\circledR}$ ). NCM fulfil the key prerequisites for the introduction of the technology to the clinic trial phases and the market, that is, they are in line with regulatory requirements and provide the possibility of qualified industrial large-scale production. Furthermore, NCM exhibit flexibility in terms of the route of ad- 
ministration and have been used for oral, parenteral, ophthalmic, and topical delivery of a variety of compounds.

The characterization of NCM delivery systems is an area that requires the formulation development and production of a products of high quality. Ideally, NCM should be in the nano range with a PDI $<0.500$, determined using DLS and Photon Correlation Spectroscopy (PCS) in combination with Laser Diffraction (LD). However, PCS and DLS cannot be used to characterize the shape, surface morphology, and elemental composition of NCM and additional analytical tools are required. Therefore, TEM, SEM, and EDX should be used to assess the shape and surface morphology of NCM in the solid-state and dispersions. The crystalline nature and polymorphic transition of NCM are characterised using DSC, TGA, PXRD, and FTIR/Raman spectroscopy to investigate potential interactions between the API and excipients to be used. Laser Doppler Anemometry (LDA) is used to establish electrophoretic mobility and the ZP of NCM, which should be $>+30 \mathrm{mV}$ or $<-30 \mathrm{mV}$ in dispersion.

Other characterisations perhaps not considered the most fundamental but worth additional exploration include two-dimensional (2D) nuclear magnetic resonance (NMR) techniques such as correlation spectroscopy (COSY), diffusion-ordered spectroscopy (DOSY), and cross-polarization magic-angle spinning (CPMAS). These are used to generate additional information in terms of the stability of the nanocarriers in solution and solid-state in addition to the presence of hydrogen bonding.

Author Contributions: Conceptualization, B.A.W.; writing-original draft preparation, B.A.W. and M.A.; writing-review and editing, B.A.W., M.A., L.L.M. and P.A.M. All authors have read and agreed to the published version of the manuscript.

Funding: This research was not funded with an external research grant.

Institutional Review Board Statement: Not applicable

Informed Consent Statement: Not applicable

Acknowledgments: The authors acknowledge the Research Committee of Rhodes University (P.A.M.).

Conflicts of Interest: The authors declare no conflict of interest.

\section{References}

1. Tiwari, G.; Tiwari, R.; Bannerjee, S.; Bhati, L.; Pandey, S.; Pandey, P.; Sriwastawa, B. Drug delivery systems: An updated review. Int. J. Pharm. Investig. 2012, 2, 2. [CrossRef] [PubMed]

2. Farokhzad, O.C.; Langer, R. Impact of Nanotechnology on Drug Discovery \& Development Pharmanext. ACS Nano 2009, 3, 16-20. [PubMed]

3. Junghanns, J.U.A.H.; Müller, R.H. Nanocrystal technology, drug delivery and clinical applications. Int. J. Nanomed. 2008, 3, 295-309. [CrossRef]

4. Müller, R.H. Lipid nanoparticles: Recent advances. Adv. Drug Deliv. Rev. 2007, 59, 375-376. [CrossRef]

5. Muller, R.H.; Keck, C.M. Challenges and solutions for the delivery of biotech drugs-A review of drug nanocrystal technology and lipid nanoparticles. J. Biotechnol. 2004, 113, 151-170. [CrossRef]

6. $\quad$ Blagden, N.; de Matas, M.; Gavan, P.T.; York, P. Crystal engineering of active pharmaceutical ingredients to improve solubility and dissolution rates. Adv. Drug Deliv. Rev. 2007, 59, 617-630. [CrossRef]

7. Subramanian, S.; Zaworotko, M.J. Manifestations of noncovalent bonding in the solid state. 6 . [H 4 (cyclam)] $4+(\mathrm{cyclam}=$ 1,4,8,11-tetraazacyclotetradecane) as a template for crystal engineering of network hydrogen-bonded solids. Can. J. Chem. 1995, 73, 414-424. [CrossRef]

8. Desiraju, G.R. Crystal Engineering: The design of Organic Solids. J. Appl. Crystallogr. 1991, 24, 265. [CrossRef]

9. Desiraju, G.R. Supramolecular Synthons in Crystal Engineering. Angew. Chem. Int. Ed. 1995, 34, 2311-2327. [CrossRef]

10. Aakeroy, C.B.; Aakeroy, A.; Sinha, A.S. Co-Crystals: Introduction and Scope; Royal Society of Chemistry: London, UK, 2018; Volume 11.

11. Bolton, O.; Matzger, A.J. Improved stability and smart-material functionality realized in an energetic cocrystal. Angezw. Chem. Int. Ed. 2011, 50, 8960-8963. [CrossRef]

12. Brittain, H.G. Pharmaceutical cocrystals: The coming wave of new drug substances. J. Pharm. Sci. 2013, 102, 311-317. [CrossRef]

13. Brittain, H.G. Cocrystal Systems of Pharmaceutical Interest: 2010. Cryst. Growth Des. 2011, 36, 361-381. [CrossRef]

14. Sekhon, B. Pharmaceutical co-crystals-A review. ARS Pharm. 2009, 150, 99-117. 
15. Merisko-Liversidge, E.; Liversidge, G.G. Nanosizing for oral and parenteral drug delivery: A perspective on formulating poorlywater soluble compounds using wet media milling technology. Adv. Drug Deliv. Rev. 2011, 63, 427-440. [CrossRef] [PubMed]

16. Merisko-Liversidge, E.; Liversidge, G.G.; Cooper, E.R. Nanosizing: A formulation approach for poorly-water-soluble compounds. Eur. J. Pharm. Sci. 2003, 18, 113-120. [CrossRef]

17. Sinha, B.; Muller, R.H.; Moschwitzer, J.P. Bottom-up approaches for preparing drug nanocrystals: Formulations and factors affecting particle size. Int. J. Pharm. 2013, 8, 384-392. [CrossRef] [PubMed]

18. De Waard, H.; Frijlink, H.W.; Hinrichs, W.L.J. Bottom-up preparation techniques for nanocrystals of lipophilic drugs. Pharm. Res. 2011, 28, 1220-1223. [CrossRef]

19. Witika, B.A.; Smith, V.J.; Walker, R.B. A comparative study of the effect of different stabilizers on the critical quality attributes of self-assembling nano co-crystals. Pharmaceutics 2020, 12, 182. [CrossRef]

20. Choi, J.Y.; Yoo, J.Y.; Kwak, H.S.; Nam, B.U.; Lee, J. Role of polymeric stabilizers for drug nanocrystal dispersions. Curr. Appl. Phys. 2005, 5, 472-474. [CrossRef]

21. Ghosh, I.; Bose, S.; Vippagunta, R.; Harmon, F. Pharmaceutical Nanotechnology Nanosuspension for improving the bioavailability of a poorly soluble drug and screening of stabilizing agents to inhibit crystal growth. Int. J. Pharm. 2011, 409, 260-268. [CrossRef]

22. Raghava Srivalli, K.M.; Mishra, B. Drug nanocrystals: A way toward scale-up. Saudi Pharm. J. 2016, 24, 386-404. [CrossRef]

23. Al Shaal, L.; Müller, R.H.; Keck, C.M. Preserving hesperetin nanosuspensions for dermal application. Pharmazie 2010, 65, 86-92. [CrossRef] [PubMed]

24. Piao, H.; Kamiya, N.; Cui, F.; Goto, M. Preparation of a solid-in-oil nanosuspension containing l-ascorbic acid as a novel long-term stable topical formulation. Int. J. Pharm. 2011, 420, 156-160. [CrossRef]

25. Patel, D.A.; Patel, M.R.; Patel, K.R.; Patel, N.M. Buccal mucosa as a route for systemic drug delivery: A review. Int. J. Drug Dev. Res. 2012, 1, 15-30.

26. Dressman, J.B.; Reppas, C. In vitro-in vivo correlations for lipophilic, poorly water-soluble drugs. Eur. J. Pharm. Sci. 2000, 11, S73-S80. [CrossRef]

27. Kesisoglou, F.; Panmai, S.; Wu, Y. Nanosizing-Oral formulation development and biopharmaceutical evaluation. Adv. Drug Deliv. Rev. 2007, 59, 631-644. [CrossRef]

28. Wu, Y.; Loper, A.; Landis, E.; Hettrick, L.; Novak, L.; Lynn, K.; Chen, C.; Thompson, K.; Higgins, R.; Batra, U.; et al. The role of biopharmaceutics in the development of a clinical nanoparticle formulation of MK-0869: A Beagle dog model predicts improved bioavailability and diminished food effect on absorption in human. Int. J. Pharm. 2004, 285, 135-146. [CrossRef] [PubMed]

29. Edelhauser, H.F.; Rowe-Rendleman, C.L.; Robinson, M.R.; Dawson, D.G.; Chader, G.J.; Grossniklaus, H.E.; Rittenhouse, K.D.; Wilson, C.G.; Weber, D.A.; Kuppermann, B.D.; et al. Ophthalmic drug delivery systems for the treatment of retinal diseases: Basic research to clinical applications. Investig. Ophthalmol. Vis. Sci. 2010, 51, 5403-5420. [CrossRef]

30. Makoni, P.A.; Khamanga, S.M.; Walker, R.B. Muco-adhesive clarithromycin-loaded nanostructured lipid carriers for ocular delivery: Formulation, characterization, cytotoxicity and stability. J. Drug Deliv. Sci. Technol. 2020, 61, 102171. [CrossRef]

31. Kassem, M.A.; Abdel Rahman, A.A.; Ghorab, M.M.; Ahmed, M.B.; Khalil, R.M. Nanosuspension as an ophthalmic delivery system for certain glucocorticoid drugs. Int. J. Pharm. 2007, 340, 126-133. [CrossRef]

32. Baba, K.; Nishida, K. Steroid nanocrystals prepared using the nano spray dryer B-90. Pharmaceutics 2013, 5, 107-114. [CrossRef]

33. Ali, H.S.M.; York, P.; Ali, A.M.A.; Blagden, N. Hydrocortisone nanosuspensions for ophthalmic delivery: A comparative study between microfluidic nanoprecipitation and wet milling. J. Control Release 2011, 149, 175-181. [CrossRef]

34. Ganta, S.; Paxton, J.W.; Baguley, B.C.; Garg, S. Formulation and pharmacokinetic evaluation of an asulacrine nanocrystalline suspension for intravenous delivery. Int. J. Pharm. 2009, 367, 179-186. [CrossRef]

35. Ben Zirar, S.; Astier, A.; Muchow, M.; Gibaud, S. Comparison of nanosuspensions and hydroxypropyl- $\beta$-cyclodextrin complex of melarsoprol: Pharmacokinetics and tissue distribution in mice. Eur. J. Pharm. Biopharm. 2008, 70, 649-656. [CrossRef]

36. Zhang, D.; Chen, M.; Zheng, T.; Wang, S. Preparation and Characterization of an Oridonin Nanosuspension for Solubility and Dissolution Velocity Enhancement AU—Gao, Lei. Drug Dev. Ind. Pharm. 2007, 33, 1332-1339. [CrossRef]

37. Rabinow, B.; Kipp, J.; Papadopoulos, P.; Wong, J.; Glosson, J.; Gass, J.; Sun, C.S.; Wielgos, T.; White, R.; Cook, C.; et al. Itraconazole IV nanosuspension enhances efficacy through altered pharmacokinetics in the rat. Int. J. Pharm. 2007, 339, 251-260. [CrossRef] [PubMed]

38. Li, Z.; Sun, M.; Guo, C.; Yu, A.; Xi, Y.; Cui, J.; Lou, H.; Zhai, G. Preparation and characterization of intravenously injectable curcumin nanosuspension AU—Gao, Yan. Drug Deliv. 2011, 18, 131-142. [CrossRef]

39. Lu, Y.; Wang, Z.H.; Li, T.; McNally, H.; Park, K.; Sturek, M. Development and evaluation of transferrin-stabilized paclitaxel nanocrystal formulation. J. Control Release 2014, 176, 76-85. [CrossRef] [PubMed]

40. Sarnes, A.; Kovalainen, M.; Häkkinen, M.R.; Laaksonen, T.; Laru, J.; Kiesvaara, J.; Ilkka, J.; Oksala, O.; Rönkkö, S.; Järvinen, K.; et al. Nanocrystal-based per-oral itraconazole delivery: Superior in vitro dissolution enhancement versus Sporanox ${ }^{\circledR}$ is not realized in in vivo drug absorption. J. Control Release 2014, 180, 109-116. [CrossRef] [PubMed]

41. Müller, R.H.; Jacobs, C. Buparvaquone mucoadhesive nanosuspension: Preparation, optimisation and long-term stability. Int. J. Pharm. 2002, 237, 151-161. [CrossRef]

42. Witika, B.A.; Smith, V.J.; Walker, R.B. Quality by Design Optimization of Cold Sonochemical Synthesis of Zidovudine-Lamivudine Nanosuspensions. Pharmaceutics 2020, 12, 367. [CrossRef] [PubMed] 
43. Aucamp, M.; Milne, M. The physical stability of drugs linked to quality-by-design (QbD) and in-process technology (PAT) perspectives. Eur. J. Pharm. Sci. 2019, 139, 105057. [CrossRef]

44. Shegokar, R.; Müller, R.H. Nanocrystals: Industrially feasible multifunctional formulation technology for poorly soluble actives. Int. J. Pharm. 2010, 399, 129-139. [CrossRef] [PubMed]

45. Rabinow, B.E. Nanosuspensions in drug delivery. Nat. Rev. Drug Discov. 2004, 3, 785. [CrossRef]

46. Muller, R.H.; Jacobs, C.; Kayser, O. Nanosuspensions as particulate drug formulations in therapy: Rationale for development and what we can expect for the future. Adv. Drug Deliv. Rev. 2001, 47, 3-19. [CrossRef]

47. Keck, C.M.; Müller, R.H. Drug nanocrystals of poorly soluble drugs produced by high pressure homogenisation. Eur. J. Pharm. Biopharm. 2006, 62, 3-16. [CrossRef]

48. Li, X.; Zhou, L.; Ma, J.; Gao, L.; Wang, X.; Liu, G. Drug nanocrystals: In vivo performances. J. Control Release 2012, 160, 418-430. [CrossRef]

49. Lu, Y.; Li, Y.; Wu, W. Injected nanocrystals for targeted drug delivery. Acta Pharm. Sin. B 2016, 6, 106-113. [CrossRef]

50. Juhnke, M.; Martin, D.; John, E. Generation of wear during the production of drug nanosuspensions by wet media milling. Eur. J. Pharm. Biopharm. 2012, 81, 214-222. [CrossRef]

51. Van Eerdenbrugh, B.; Van den Mooter, G.; Augustijns, P. Top-down production of drug nanocrystals: Nanosuspension stabilization, miniaturization and transformation into solid products. Int. J. Pharm. 2008, 364, 64-75. [CrossRef] [PubMed]

52. Karashima, M.; Kimoto, K.; Yamamoto, K.; Kojima, T.; Ikeda, Y. A novel solubilization technique for poorly soluble drugs through the integration of nanocrystal and cocrystal technologies. Eur. J. Pharm. Biopharm. 2016, 107, 142-150. [CrossRef]

53. De Smet, L.; Saerens, L.; De Beer, T.; Carleer, R.; Adriaensens, P.; Van Bocxlaer, J.; Vervaet, C.; Remon, J.P. Formulation of itraconazole nanococrystals and evaluation of their bioavailability in dogs. Eur. J. Pharm. Biopharm. 2014, 87, 107-113. [CrossRef]

54. Witika, B.A.; Smith, V.J.; Walker, R.B. Top-Down Synthesis of a Lamivudine-Zidovudine Nano Co-Crystal. Crystals 2021, 11, 33. [CrossRef]

55. Xia, D.; Cui, Y.G. and F. Application of Precipitation Methods for the Production of Water-insoluble Drug Nanocrystals: Production Techniques and Stability of Nanocrystals. Curr. Pharm. Des. 2014, 20, 408-435. [CrossRef] [PubMed]

56. Dalvi, S.V.; Yadav, M.D. Effect of ultrasound and stabilizers on nucleation kinetics of curcumin during liquid antisolvent precipitation. Ultrason. Sonochem. 2015, 24, 114-122. [CrossRef] [PubMed]

57. Sander, J.R.G.; Bučar, D.K.; Henry, R.F.; Zhang, G.G.Z.; MacGillivray, L.R. Pharmaceutical nano-cocrystals: Sonochemical synthesis by solvent selection and use of a surfactant. Angew. Chem. Int. Ed. 2010, 49, 7284-7288. [CrossRef]

58. Huang, Y.; Li, J.-M.; Lai, Z.-H.; Wu, J.; Lu, T.-B.; Chen, J.-M. Phenazopyridine-phthalimide nano-cocrystal: Release rate and oral bioavailability enhancement. Eur. J. Pharm. Sci. 2017. [CrossRef]

59. Hong, C.; Xie, Y.; Yao, Y.; Li, G.; Yuan, X.; Shen, H. A Novel strategy for pharmaceutical cocrystal generation without knowledge of stoichiometric ratio: Myricetin cocrystals and a ternary phase diagram. Pharm. Res. 2015, 32, 47-60. [CrossRef] [PubMed]

60. Liu, M.; Hong, C.; Li, G.; Ma, P.; Xie, Y. The generation of myricetin-nicotinamide nanococrystals by top down and bottom up technologies. Nanotechnology 2016, 27. [CrossRef] [PubMed]

61. Allen, F.H. The Cambridge Structural Database: A quarter of a million crystal structures and rising. Acta Crystallogr. Sect. B Struct. Sci. 2002, 58, 380-388. [CrossRef] [PubMed]

62. Bruno, I.J.; Cole, J.C.; Edgington, P.R.; Kessler, M.; Macrae, C.F.; McCabe, P.; Pearson, J.; Taylor, R. New software for searching the Cambridge Structural Database and visualizing crystal structures. Acta Crystallogr. B 2002, 58, 389-397. [CrossRef] [PubMed]

63. Vance, E.J. Growth and Perfection of Crystals. J. Am. Chem. Soc. 1959, 81, 3489-3490. [CrossRef]

64. Doremus, R.; Roberts, B.; Turnbull, D. Growth and Perfection of Crystals. J. Polym. Sci. 1959, 38, 2053-2054. [CrossRef]

65. Gagniere, E.; Mangin, D.; Veesler, S.; Puel, F. Co-Crystallization in Solution and Scale-up Issues; Royal Society of Chemistry: London, UK, 2012; ISBN 9781849733502.

66. Cho, E.J.; Holback, H.; Liu, K.C.; Abouelmagd, S.A.; Park, J.; Yeo, Y. Nanoparticle characterization: State of the art, challenges, and emerging technologies. Mol. Pharm. 2013, 10, 2093-2110. [CrossRef]

67. Stefaniak, A.B.; Hackley, V.A.; Roebben, G.; Ehara, K.; Hankin, S.; Postek, M.T.; Lynch, I.; Fu, W.-E.; Linsinger, T.P.J.; Thünemann, A.F. Nanoscale reference materials for environmental, health and safety measurements: Needs, gaps and opportunities. Nanotoxicology 2013, 7, 1325-1337. [CrossRef]

68. Lewinski, N.; Colvin, V.; Drezek, R. Cytotoxicity of nanopartides. Small 2008, 4, 26-49. [CrossRef] [PubMed]

69. Almeida, J.P.M.; Chen, A.L.; Foster, A.; Drezek, R. In vivo biodistribution of nanoparticles. Nanomedicine 2011, 6, 815-835. [CrossRef]

70. Malvern Instruments Ltd. Surfactant micelle characterization using dynamic light scattering. Malvern Instrum. 2006, MRK80901, 1-5.

71. Malvern Instruments White Paper: Dynamic Light Scattering, Common terms defined; Malvern Instruments Limited: Worcestershire, UK, 2011; pp. 1-6.

72. Lu, X.-Y.; Wu, D.-C.; Li, Z.-J.; Chen, G.-Q. Polymer nanoparticles. Prog. Mol. Biol. Transl. Sci. 2011, 104, 299-323. [CrossRef] [PubMed]

73. Hoo, C.M.; Starostin, N.; West, P.; Mecartney, M.L. A comparison of atomic force microscopy (AFM) and dynamic light scattering (DLS) methods to characterize nanoparticle size distributions. J. Nanopart. Res. 2008, 10, 89-96. [CrossRef] 
74. Boyd, R.D.; Pichaimuthu, S.K.; Cuenat, A. New approach to inter-technique comparisons for nanoparticle size measurements; using atomic force microscopy, nanoparticle tracking analysis and dynamic light scattering. Colloids Surfaces A Physicochem. Eng. Asp. 2011, 387, 35-42. [CrossRef]

75. Mahl, D.; Diendorf, J.; Meyer-Zaika, W.; Epple, M. Possibilities and limitations of different analytical methods for the size determination of a bimodal dispersion of metallic nanoparticles. Colloids Surfaces A Physicochem. Eng. Asp. 2011, 377, 386-392. [CrossRef]

76. Murdock, R.C.; Braydich-Stolle, L.; Schrand, A.M.; Schlager, J.J.; Hussain, S.M. Characterization of nanomaterial dispersion in solution prior to in vitro exposure using dynamic light scattering technique. Toxicol. Sci. 2008, 101, 239-253. [CrossRef]

77. Kirby, B.J.; Hasselbrink, E.F. Zeta potential of microfluidic substrates: 2. Data for polymers. Electrophoresis 2004, 25, 203-213. [CrossRef] [PubMed]

78. Kirby, B.J.; Hasselbrink, E.F. Zeta potential of microfluidic substrates: 1. Theory, experimental techniques, and effects on separations This. Electrophoresis 2004, 25, 187-202. [CrossRef]

79. Malamatari, M.; Somavarapu, S.; Taylor, K.M.; Buckton, G. Solidification of nanosuspensions for the production of solid oral dosage forms and inhalable dry powders Solidification of nanosuspensions for the production of solid oral dosage forms and inhalable dry powders. Expert Opin. Drug Deliv. 2016. [CrossRef]

80. Peng, H.R.; Gong, M.M.; Chen, Y.Z.; Liu, F. Thermal stability of nanocrystalline materials: Thermodynamics and kinetics. Int. Mater. Rev. 2017, 62, 303-333. [CrossRef]

81. Verdonck, E.; Schaap, K.; Thomas, L.C. A discussion of the principles and applications of Modulated Temperature DSC (MTDSC). Int. J. Pharm. 1999, 192, 3-20. [CrossRef]

82. Chogale, M.M.; Ghodake, V.N.; Patravale, V.B. Performance parameters and characterizations of nanocrystals: A brief review. Pharmaceutics 2016, 8, 26. [CrossRef]

83. Kocbek, P.; Baumgartner, S.; Kristl, J. Preparation and evaluation of nanosuspensions for enhancing the dissolution of poorly soluble drugs. Int. J. Pharm. 2006, 312, 179-186. [CrossRef] [PubMed]

84. Valo, H.; Kovalainen, M.; Laaksonen, P.; Häkkinen, M.; Auriola, S.; Peltonen, L.; Linder, M.; Järvinen, K.; Hirvonen, J.; Laaksonen, T. Immobilization of protein-coated drug nanoparticles in nanofibrillar cellulose matrices-Enhanced stability and release. J. Control Release 2011, 156, 390-397. [CrossRef]

85. Clas, S.; Dalton, C.; Hancock, B. Differential scanning calorimetry: Applications in drug development. Pharm. Sci. Technol. Today 1999, 2, 311-320. [CrossRef]

86. Mourdikoudis, S.; Pallares, R.M.; Thanh, N.T.K. Characterization techniques for nanoparticles: Comparison and complementarity upon studying nanoparticle properties. Nanoscale 2018, 10, 12871-12934. [CrossRef] [PubMed]

87. Ingham, B.; Toney, M.F. X-Ray Diffraction for Characterizing Metallic Films. In Metallic Films for Electronic, Optical and Magnetic Applications: Structure, Processing and Properties; Elsevier Ltd.: Amsterdam, The Netherlands, 2013; pp. 3-38. ISBN 9780857090577.

88. Müllertz, A.; Perrie, Y.; Rades, T. Advances in Delivery Science and Technology: Analytical Techniques in the Pharmaceutical Sciences; Rathbone, M.J., Ed.; Springer Science and Business Media LLC: New York, NY, USA, 2016; ISBN 9781493940271.

89. Engelhard, M.H.; Droubay, T.C.; Du, Y. X-ray Photoelectron Spectroscopy Applications. In Encyclopedia of Spectroscopy and Spectrometry; Elsevier: Amsterdam, The Netherlands, 2017; pp. 716-724. ISBN 9780128032244.

90. Chauhan, A. Powder XRD Technique and its Applications in Science and Technology. J. Anal. Bioanal. Tech. 2014, 5. [CrossRef]

91. Kirtansinh, G.; Piyushbhai, P.; Natubhai, P. Application of Analytical Techniques in Preformulation Study: A Review. Int. J. Pharm. Biol. Arch. 2011, 2, 1319-1326.

92. Hirsch, P.B. Elements of X-Ray Diffraction, 2nd ed.; Wesley-Addion Publishing Company: Reading, MA, USA, 1957; Volume 8, ISBN 0201610914.

93. Upadhyay, S.; Parekh, K.; Pandey, B. Influence of crystallite size on the magnetic properties of $\mathrm{Fe}_{3} \mathrm{O}_{4}$ nanoparticles. J. Alloys Compd. 2016, 678, 478-485. [CrossRef]

94. Li, W.; Zamani, R.; Rivera Gil, P.; Pelaz, B.; Ibáñez, M.; Cadavid, D.; Shavel, A.; Alvarez-Puebla, R.A.; Parak, W.J.; Arbiol, J.; et al. CuTe nanocrystals: Shape and size control, plasmonic properties, and use as SERS probes and photothermal agents. J. Am. Chem. Soc. 2013, 135, 7098-7101. [CrossRef]

95. Yan, W.; Mahurin, S.M.; Overbury, S.H.; Dai, S. Nanoengineering catalyst supports via layer-by-layer surface functionalization. Top. Catal. 2006, 39, 199-212. [CrossRef]

96. Wang, W.; Chen, X.; Cai, Q.; Mo, G.; Jiang, L.S.; Zhang, K.; Chen, Z.J.; Wu, Z.H.; Pan, W. In situ SAXS study on size changes of platinum nanoparticles with temperature. Eur. Phys. J. B 2008, 65, 57-64. [CrossRef]

97. Cipolla, D.; Wu, H.; Salentinig, S.; Boyd, B.; Rades, T.; Vanhecke, D.; Petri-Fink, A.; Rothin-Rutishauser, B.; Eastman, S.; Redelmeier, T.; et al. Formation of drug nanocrystals under nanoconfinement afforded by liposomes. RSC Adv. 2016, 6, 6223-6233. [CrossRef]

98. Li, T.; Mudie, S.; Cipolla, D.; Rades, T.; Boyd, B.J. Solid State Characterization of Ciprofloxacin Liposome Nanocrystals. Mol. Pharm. 2019, 16, 184-194. [CrossRef] [PubMed]

99. Schilt, Y.; Berman, T.; Wei, X.; Barenholz, Y.; Raviv, U. Using solution X-ray scattering to determine the high-resolution structure and morphology of PEGylated liposomal doxorubicin nanodrugs. Biochim. Biophys. Acta 2016, 1860, 108-119. [CrossRef]

100. Li, X.; Hirsh, D.J.; Cabral-Lilly, D.; Zirkel, A.; Gruner, S.M.; Janoff, A.S.; Perkins, W.R. Doxorubicin physical state in solution and inside liposomes loaded via a pH gradient. Biochim. Biophys. Acta 1998, 1415, 23-40. [CrossRef]

101. Matthew, J. Surface Analysis by AUGER and X-Ray Photoelectron Spectroscopy; Briggs, D., Grant, J.T., Eds.; John Wiley \& Sons, Ltd.: Chichester, UK, 2004; Volume 36, ISBN 1-901019-04-7. 
102. Ray, S.; Shard, A.G. Quantitative Analysis of Adsorbed Proteins by X-ray Photoelectron Spectroscopy. Anal. Chem. 2011, 83, 8659-8666. [CrossRef]

103. Beloqui Redondo, A.; Jordan, I.; Ziazadeh, I.; Kleibert, A.; Giorgi, J.B.; Wörner, H.J.; May, S.; Abbas, Z.; Brown, M.A. NanoparticleInduced Charge Redistribution of the Air-Water Interface. J. Phys. Chem. C 2015, 119, 2661-2668. [CrossRef]

104. Qiu, L.; Liu, F.; Zhao, L.; Ma, Y.; Yao, J. Comparative XPS study of surface reduction for nanocrystalline and microcrystalline ceria powder. Appl. Surf. Sci. 2006, 252, 4931-4935. [CrossRef]

105. Chow, S.F.; Wan, K.Y.; Cheng, K.K.; Wong, K.W.; Sun, C.C.; Baum, L.; Chow, A.H.L. Development of highly stabilized curcumin nanoparticles by flash nanoprecipitation and lyophilization. Eur. J. Pharm. Biopharm. 2015, 94, 436-449. [CrossRef]

106. Dong, Y.; Feng, S.S. Methoxy poly(ethylene glycol)-poly(lactide) (MPEG-PLA) nanoparticles for controlled delivery of anticancer drugs. Biomaterials 2004, 25, 2843-2849. [CrossRef]

107. Mu, L.; Feng, S.S. A novel controlled release formulation for the anticancer drug paclitaxel (Taxol ${ }^{\circledR}$ ): PLGA nanoparticles containing vitamin E TPGS. J. Control Release 2003, 86, 33-48. [CrossRef]

108. El-Hagrasy, A.S.; Morris, H.R.; D'Amico, F.; Lodder, R.A.; Drennen, J.K. Near-infrared spectroscopy and imaging for the monitoring of powder blend homogeneity. J. Pharm. Sci. 2001, 90, 1298-1307. [CrossRef]

109. Robert, M.S.; Webster, F.X.; Kiemle, D.J.; Bryce, D.L. Spectrometric Identification of Organic Compounds, 3rd ed.; Wiley: Hoboken, NJ, USA, 1976; Volume 30, ISBN 0471393622.

110. Lai, F.; Pini, E.; Corrias, F.; Perricci, J.; Manconi, M.; Fadda, A.M.; Sinico, C. Formulation strategy and evaluation of nanocrystal piroxicam orally disintegrating tablets manufacturing by freeze-drying. Int. J. Pharm. 2014, 467, 27-33. [CrossRef] [PubMed]

111. Witika, B.A. Formulation Development, Manufacture and Evaluation of a Lamivudine-Zidovudine Nano Co-Crystal ThermoResponsive Suspension. Ph.D. Thesis, Rhodes University, Makhanda, South Africa, 2020.

112. Sharma, P.; Zujovic, Z.D.; Bowmaker, G.A.; Denny, W.A.; Garg, S. Evaluation of a crystalline nanosuspension: Polymorphism, process induced transformation and in vivo studies. Int. J. Pharm. 2011, 408, 138-151. [CrossRef] [PubMed]

113. Loridant, S.; Lucazeau, G.; Le Bihan, T. A high-pressure Raman and X-ray diffraction study of the perovskite SrCeO 3 . J. Phys. Chem. Solids 2002, 63, 1983-1992. [CrossRef]

114. Colomban, P. ReviewRaman Studies of Inorganic Gels and of Their Sol-to-Gel, Gel-to-Glass and Glass-to-Ceramics Transformation. J. Raman Spectrosc. 1996, 27, 747-758. [CrossRef]

115. Durán, P.; Capel, F.; Tartaj, J.; Gutierrez, D.; Moure, C. Heating-rate effect on the BaTiO3 formation by thermal decomposition of metal citrate polymeric precursors. Solid State Ion. 2001, 141-142, 529-539. [CrossRef]

116. Parayanthal, P.; Pollak, F.H. Raman Scattering in Alloy Semiconductors: "Spatial Correlation" Model. Phys. Rev. Lett. 1984, 52, 1822-1825. [CrossRef]

117. Ager, J.W.; Veirs, D.K.; Rosenblatt, G.M. Spatially resolved Raman studies of diamond films grown by chemical vapor deposition. Phys. Rev. B 1991, 43, 6491-6499. [CrossRef]

118. Critchley, L. Is Raman Spectroscopy Useful in Nanomaterial Analysis? Available online: https://www.azonano.com/article. aspx?ArticleID=5273 (accessed on 21 March 2021).

119. Mu, S.; Li, M.; Guo, M.; Yang, W.; Wang, Y.; Li, J.; Fu, Q.; He, Z. Spironolactone nanocrystals for oral administration: Different pharmacokinetic performances induced by stabilizers. Colloids Surfaces B Biointerfaces 2016, 147, 73-80. [CrossRef]

120. De Waard, H.; De Beer, T.; Hinrichs, W.L.J.; Vervaet, C.; Remon, J.P.; Frijlink, H.W. Controlled crystallization of the lipophilic drug fenofibrate during freeze-drying: Elucidation of the mechanism by in-line raman spectroscopy. AAPS J. 2010, 12, 569-575. [CrossRef] [PubMed]

121. Swarbick, J. Encyclopedia of Pharmaceutical Technology, 3rd ed.; CRC Press: Boca Raton, FL, USA, 2018 ; ISBN 0824725387.

122. Klienebudde, P. The Crystallite-Gel-Model for microcrystalline Celluslose in Wet Granulation, Extrusion and Spheronization. Pharm. Res. 1997, 14, 804-809. [CrossRef] [PubMed]

123. Pitchayajittipong, C.; Price, R.; Shur, J.; Kaerger, J.S.; Edge, S. Characterisation and functionality of inhalation anhydrous lactose. Int. J. Pharm. 2010, 390, 134-141. [CrossRef] [PubMed]

124. Crisp, J.L.; Dann, S.E.; Blatchford, C.G. Antisolvent crystallization of pharmaceutical excipients from aqueous solutions and the use of preferred orientation in phase identification by powder X-ray diffraction. Eur. J. Pharm. Sci. 2011, 42, 568-577. [CrossRef]

125. Ho, R.; Naderi, M.; Heng, J.Y.Y.; Williams, D.R.; Thielmann, F.; Bouza, P.; Keith, A.R.; Thiele, G.; Burnett, D.J. Effect of milling on particle shape and surface energy heterogeneity of needle-Shaped crystals. Pharm. Res. 2012, 29, 2806-2816. [CrossRef] [PubMed]

126. Kubavat, H.A.; Shur, J.; Ruecroft, G.; Hipkiss, D.; Price, R. Investigation into the influence of primary crystallization conditions on the mechanical properties and secondary processing behaviour of fluticasone propionate for carrier based dry powder inhaler formulations. Pharm. Res. 2012, 29, 994-1006. [CrossRef]

127. Otte, A.; Teresa, C. Assessment of Milling-Induced Disorder of Two Pharmaceutical Compounds. J. Pharm. Sci. 2012, 101, 322-332. [CrossRef]

128. Park, M.H.; Kim, J.H.; Jeon, J.W.; Park, J.K.; Lee, B.J.; Suh, G.H.; Cho, C.W. Preformulation studies of bee venom for the preparation of bee venom-loaded PLGA particles. Molecules 2015, 20, 15072-15083. [CrossRef]

129. Patel, P.; Ahir, K.; Patel, V.; Manani, L.; Patel, C. Drug-Excipient compatibility studies: First step for dosage form development. Pharma Innov. J. 2015, 4, 14-20.

130. Ruska, E.; Knoll, M.; Ruska, E. Das Elektronenmikroskop. Zeitschrift Phys. 1932, 78, 318-339. [CrossRef] 
131. Kuntsche, J.; Horst, J.C.; Bunjes, H. Cryogenic transmission electron microscopy (cryo-TEM) for studying the morphology of colloidal drug delivery systems. Int. J. Pharm. 2011, 417, 120-137. [CrossRef]

132. Klang, V.; Matsko, N.B. Electron microscopy of pharmaceutical systems. Adv. Imaging Electron. Phys. 2014, 181, 125-208. [CrossRef]

133. Swartz, M.E. Ultra performance liquid chromatography (UPLC): An introduction. Sep. Sci. Re-Defin. 2005, 586, 8-14.

134. Hamilton, R.J.; Sewell, P.A. Introduction to High Performance Liquid Chromatography; Hamilton, R.J., Sewell, P.A., Eds.; Springer: Dordrecht, The Netherlands, 1982; Volume 15, ISBN 978-94-009-5938-5.

135. Davankov, V.A. Separation of enantiomeric compounds using chiral HPLC systems. A brief review of general principles, advances, and development trends. Chromatographia 1989, 27, 475-482. [CrossRef]

136. Aygün, Ş.F.; Özcimder, M. A comparison of normal(-CN) and reversed (C-18) phase chromatographic behaviour of polycyclic aromatic hydrocarbons. Turk. J. Chem. 1996, 20, 269-275.

137. de Villiers, A.; Lestremau, F.; Szucs, R.; Gélébart, S.; David, F.; Sandra, P. Evaluation of ultra performance liquid chromatography. Part I. Possibilities and limitations. J. Chromatogr. A 2006, 1127, 60-69. [CrossRef]

138. Vervoort, R.J.M.; Debets, A.J.J.; Claessens, H.A.; Cramers, C.A.; De Jong, G.J. Optimisation and characterisation of silicabased reversed-phase liquid chromatographic systems for the analysis of basic pharmaceuticals. J. Chromatogr. A 2000, 897, 1-22. [CrossRef]

139. Snyder, R.J.; Kirkland, J.; Glajch, J.L. Practical HPLC Method Development, 2nd ed.; John Wiley and Sons: New York, NY, USA, 1997; Volume 41.

140. Simpson, C. Practical HPLC; The Whitefriars Press: London, UK, 1976.

141. Raghavan, R.; Joseph, J. Chromatographic Methodsof Analysis-High Performance Lquid Chromatography, Enclopedia or Pharmaceutical Technology; Informa Healthcare USA: New York, NY, USA, 2002.

142. Young, C.S.; Weigand, R.J. An efficient approach to column selection in HPLC method development. LC-GC N. Am. 2020, 20, 464-473.

143. Ewing, G.W.; Jordan, J. Instrumental Methods of Chemical Analysis, 5th ed.; Himalaya Publishing House: New Delhi, India, 1955; Volume 27.

144. Beckett, A.H.; Stenlake, J.B. Practical Pharmaceutical Chemistry; John Wiley \& Sons, Ltd.: Hoboken, NJ, USA, 1963 ; Volume 52.

145. Siddiqui, M.R.; AlOthman, Z.A.; Rahman, N. Analytical techniques in pharmaceutical analysis: A review. Arab. J. Chem. 2017, 10, S1409-S1421. [CrossRef]

146. Butnariu, M.; Coradini, C.Z. Evaluation of Biologically Active Compounds from Calendula officinalis Flowers using Spectrophotometry. Chem. Cent. J. 2012, 6, 35. [CrossRef] [PubMed]

147. Antosiewicz, J.M.; Shugar, D. UV-Vis spectroscopy of tyrosine side-groups in studies of protein structure. Part 1: Basic principles and properties of tyrosine chromophore. Biophys. Rev. 2016, 8, 151-161. [CrossRef]

148. Braun, C.S.; Kueltzo, L.A.; Russell Middaugh, C. Ultraviolet absorption and circular dichroism spectroscopy of nonviral gene delivery complexes. Methods Mol. Med. 2001, 65, 253-284. [CrossRef]

149. Giovannetti, R. The Use of Spectrophotometry UV-Vis for the Study of Porphyrins. In Macro to Nano Spectroscopy; IntechOpen: Rijeka, Croatia, 2012.

150. Owen, T. Fundamentals of UV-Visible Spectroscopy: A Primer; Agilent Technologies: Waldbronn, Germany, 2000; ISBN 9788578110796.

151. Parnis, J.M.; Oldham, K.B. Beyond the beer-lambert law: The dependence of absorbance on time in photochemistry. J. Photochem. Photobiol. A Chem. 2013, 267, 6-10. [CrossRef]

152. Allen, H.C.; Brauers, T.; Finlayson-Pitts, B.J. Illustration of Deviations in the Beer-Lambert Law in an Instrumental Analysis Laboratory: Measuring Atmospheric Pollutants by Differential Optical Absorption Spectrometry. J. Chem. Educ. 1997, 74, 1459. [CrossRef]

153. Ernst, O.; Zor, T. Linearization of the Bradford protein assay. J. Vis. Exp. 2010, 1-6. [CrossRef]

154. Baker, W.B.; Parthasarathy, A.B.; Busch, D.R.; Mesquita, R.C.; Greenberg, J.H.; Yodh, A.G. Modified Beer-Lambert law for blood flow. Biomed. Opt. Express 2014, 5, 4053. [CrossRef] [PubMed]

155. Peltonen, L.; Strachan, C. Understanding critical quality attributes for nanocrystals from preparation to delivery. Molecules 2015, 20, 22286-22300. [CrossRef] [PubMed]

156. Chen, Y.; Li, T. Cellular Uptake Mechanism of Paclitaxel Nanocrystals Determined by Confocal Imaging and Kinetic Measurement. AAPS J. 2015, 17, 1126-1134. [CrossRef]

157. Witika, B.A.; Walker, R.B. Development, manufacture and characterization of niosomes for the delivery for nevirapine. Pharmazie 2019, 74, 91-96. [CrossRef] [PubMed]

158. Makoni, P.A.; Kasongo, K.W.; Walker, R.B. Short Term Stability Testing of Efavirenz-Loaded Solid Lipid Nanoparticle (SLN) and Nanostructured Lipid Carrier (NLC) Dispersions. Pharmaceutics 2019, 11, 397. [CrossRef] [PubMed]

159. Cerdeira, A.M.; Mazzotti, M.; Gander, B. Pharmaceutical Nanotechnology Miconazole nanosuspensions: Influence of formulation variables on particle size reduction and physical stability. Int. J. Pharm. 2010, 396, 210-218. [CrossRef] [PubMed]

160. Verma, S.; Kumar, S.; Gokhale, R.; Burgess, D.J. Physical stability of nanosuspensions: Investigation of the role of stabilizers on Ostwald ripening. Int. J. Pharm. 2011, 406, 145-152. [CrossRef] [PubMed]

161. Teeranachaideekul, V.; Junyaprasert, V.B.; Souto, E.B.; Müller, R.H. Development of ascorbyl palmitate nanocrystals applying the nanosuspension technology. Int. J. Pharm. 2008, 354, 227-234. [CrossRef] 
162. Center of Drug Evaluation and Research. Regulatory Classification of Pharmaceutical Co-Crystals, Guidance for Industry; US Food\&Drug Administration: Silver Spring, MD, USA, 2018.

163. Peltonen, L. Practical guidelines for the characterization and quality control of pure drug nanoparticles and nano-cocrystals in the pharmaceutical industry. Adv. Drug Deliv. Rev. 2018, 131, 101-115. [CrossRef] [PubMed]

164. Accardo, A.; Tesauro, D.; Roscigno, P.; Gianolio, E.; Paduano, L.; D’Errico, G.; Pedone, C.; Morelli, G. Physicochemical properties of mixed micellar aggregates containing CCK peptides and Gd complexes designed as tumor specific contrast agents in MRI. J. Am. Chem. Soc. 2004, 126, 3097-3107. [CrossRef] [PubMed]

165. Cheng, C.; Wei, H.; Zhang, X.Z.; Cheng, S.X.; Zhuo, R.X. Thermo-triggered and biotinylated biotin-P(NIPAAm-co-HMAAm)-bPMMA micelles for controlled drug release. J. Biomed. Mater. Res. Part A 2009, 88, 814-822. [CrossRef] [PubMed]

166. Toncheva, V.; Schacht, E.; Ng, S.Y.; Barr, J.; Heller, J. Use of block copolymers of poly(ortho esters) and poly (ethylene glycol) micellar carriers as potential tumour targeting systems. J. Drug Target. 2003, 11, 345-353. [CrossRef]

167. Yang, X.; Li, L.; Wang, Y.; Tan, Y. Preparation, pharmacokinetics and tissue distribution of micelles made of reverse thermoresponsive polymers. Int. J. Pharm. 2009, 370, 210-215. [CrossRef]

168. Tuomela, A.; Hirvonen, J.; Peltonen, L. Stabilizing agents for drug nanocrystals: Effect on bioavailability. Pharmaceutics 2016, 8, 16. [CrossRef]

169. Rad, R.T.; Mortazavi, S.A.; Vatanara, A.; Dadashzadeh, S. Enhanced dissolution rate of tadalafil nanoparticles prepared by sonoprecipitation technique: Optimization and physicochemical investigation. Iran. J. Pharm. Res. 2017, 16, 1335-1348. [CrossRef]

170. Pireddu, R.; Caddeo, C.; Valenti, D.; Marongiu, F.; Scano, A.; Ennas, G.; Lai, F.; Fadda, A.M.; Sinico, C. Diclofenac acid nanocrystals as an effective strategy to reduce in vivo skin inflammation by improving dermal drug bioavailability. Colloids Surfaces B Biointerfaces 2016, 143, 64-70. [CrossRef]

171. Hoffman, A.S. The origins and evolution of "controlled" drug delivery systems. J. Control Release 2008, 132, 153-163. [CrossRef] [PubMed]

172. Anhalt, K.; Geissler, S.; Harms, M.; Weigandt, M.; Fricker, G. Development of a new method to assess nanocrystal dissolution based on light scattering. Pharm. Res. 2012, 29, 2887-2901. [CrossRef] [PubMed]

173. Rodrigues, M.; Baptista, B.; Lopes, J.A.; Sarraguça, M.C. Pharmaceutical cocrystallization techniques. Advances and challenges. Int. J. Pharm. 2018, 547, 404-420. [CrossRef] [PubMed]

174. Agrawal, Y.; Patel, V. Nanosuspension: An approach to enhance solubility of drugs. J. Adv. Pharm. Technol. Res. 2011, 2, 81. [CrossRef] [PubMed]

175. European Medicines Agency. ICH Topic Q6A Specifications: Test Procedures and Acceptance Criteria for New Drug Substances and New Drug Products: Chemical Substances Step; ECA Academy: London, UK, 2000. 